\title{
Racial Disparities in Mortality During the 1918 Influenza Pandemic in United States Cities
}

\author{
Martin Eiermann ${ }^{\mathrm{a}}{ }^{*} 1$ \\ Elizabeth Wrigley-Field ${ }^{\mathrm{b}}{ }^{1}$ \\ James J. Feigenbaum ${ }^{\mathrm{c}}$ \\ Jonas Helgertz ${ }^{\mathrm{d}}$ \\ Elaine Hernandez \\ Courtney E. Boen ${ }^{\mathrm{f}}$
}

${ }^{\text {a }}$ ORCID 0000-0002-8514-9722; Department of Sociology; University of California Berkeley; Berkeley, CA 94720. Email: eiermann@berkeley.edu

b ORCID 0000-0003-3489-4279; Department of Sociology and Minnesota Population Center; University of Minnesota, Twin Cities; Minneapolis, MN 55455. Email: ewf@umn.edu

${ }^{\mathrm{c}}$ ORCID 0000-0002-1625-2021; Department of Economics; Boston University, Boston, MA 02215; National Bureau of Economic Research; Cambridge, MA 02138. Email: jamesf@bu.edu

d ORCID 0000-0002-2200-9095; Institute for Social Research and Data Innovation, Minnesota Population Center; University of Minnesota, Twin Cities; Minneapolis, MN 55455; Centre for Economic Demography, Department of Economic History; Lund University; 22100 Sweden. Email: helgertz@umn.edu

e ORCID 0000-0002-3295-4322; Department of Sociology; Indiana University; Bloomington, IN 47405. Email: ehernan@indiana.edu

${ }^{\mathrm{f}}$ ORCID 0000-0002-9159-6510; Department of Sociology, Population Studies and Population Aging Research Centers, Leonard Davis Institute of Health Economics; University of Pennsylvania; Philadelphia, PA 19104.Email: cboen@sas.upenn.edu

${ }^{1}$ Equal authorship

* Corresponding authors:

Martin Eiermann

Elizabeth Wrigley-Field

University of California at Berkeley

University of Minnesota, Twin Cities

410 Social Sciences Building

Berkeley, CA 94720

909 Social Sciences

Phone: (347) 836-0318

Minneapolis, MN 55455

Email: eiermann@berkeley.edu

Phone: (646) 320-6880

Email: ewf@umn.edu

KEYWORDS: 1918 influenza pandemic; racial disparities; immunological imprinting; nonpharmaceutical interventions; residential segregation

JEL CODE: I14 


\title{
Racial Disparities in Mortality During the 1918 Influenza Pandemic in United States Cities
}

\begin{abstract}
Against a backdrop of extreme racial health inequality, the 1918 influenza pandemic resulted in a striking reduction of nonwhite to white influenza and pneumonia mortality disparities in United States cities. We provide the most complete account to date of these reduced racial disparities, showing that they were almost uniform across U.S. cities. Linking data from multiple sources, we examine potential explanations for this result, including [A] city-level socio-demographic factors like segregation, [B] implementation of non-pharmaceutical interventions, [C] racial differences in exposure to the milder spring 1918 "herald wave," and [D] racial differences in early-life influenza exposures, resulting in differential immunological vulnerability to the $1918 \mathrm{flu}$. While we find little evidence for the first three explanations, we offer suggestive evidence that racial variation in childhood exposure to the 1889-1892 influenza pandemic may have shrunk racial disparities in 1918. We also highlight the possibility that differential behavioral responses to the herald wave may have protected nonwhite urban populations. By providing a comprehensive description and examination of racial inequality in mortality during the 1918 pandemic, we provide a framework for understanding disparities in infectious disease mortality that considers interactions between the natural histories of particular microbial agents and the social histories of those they infect.
\end{abstract}

\section{ACKNOWLEDGEMENTS:}

Eiermann and Wrigley-Field are listed alphabetically as equal lead authors. The authors thank Chris Muller for formative collaboration at an early stage of the project. We thank Andrew Halpern-Manners, Herb Smith, Alain Gagnon, Dylan Connor, Hampton Gaddy, and the audience at the PANSOC seminar at the Oslo Metropolitan University for their helpful comments on earlier drafts. We also thank John Hobbs, Evan Ferstl, Kelly Cain Jackson, Kenzie Maybrun, Thomas Patrick Pearson, Danial Shariat, Katarina Tolic, and Simeng Wang for invaluable research assistance. This work was supported by the Eunice Kennedy Shriver Institute for Child Health and Human Development via the Minnesota Population Center (P2CHD041023), Berkeley Population Center (P2CHD073964), the Population Studies Center at the University of Pennsylvania (R24HD044964), and the Center for Demography and Ecology at the University of Wisconsin (P2CHD047873); the National Institute on Aging via the Life Course Center at the University of Minnesota (P30AG066613); and the Fesler-Lampert Chair in Aging Studies at the University of Minnesota. 
The 1918 so-called "Spanish flu" pandemic was distinctive for at least three reasons, two of which are well known. The pandemic was immensely destructive. Globally, 50-100 million people died, including perhaps 675,000 in the United States (Ewing 2021; Spreeuwenberg et al. 2018). The virus also killed in a unique W-shaped age pattern: alongside the more universally vulnerable very young and old, young adults in their late 20 s and early 30 s experienced relatively high mortality rates. Within the United States, a third distinctive fact about the 1918 pandemic is less well known. As we show in this study, the nonwhite/white racial disparity in influenza and pneumonia mortality was around three-fourths smaller than in prior years.

This apparent narrowing of inequality is surprising for several reasons. It is the opposite of mortality trends observed during the COVID-19 pandemic and the HIV/AIDS pandemic (Hutchins et al. 2009), during which socially marginalized and oppressed groups, including poor people and communities of color, have experienced comparatively high mortality due to increased risks of disease incidence and severity. ${ }^{1}$ It also diverges from health disparities throughout the early twentieth century, when nonwhite infectious disease mortality—and total mortality—-far exceeded that of white populations in every non-pandemic year (Boustan and Margo 2016; Feigenbaum et al. 2019; Jackman and Shauman 2019; Wrigley-Field 2020). And, although the available medical care at the time was quite limited, the pattern is nevertheless notable given that the U.S. healthcare system was rife with racism; for example, during the pandemic, cities in both the North and the South opened whites-only clinics and hospitals (Bristow 1992, p. 72; Byrd and Clayton 2001).

Despite being so distinctive, these reduced mortality disparities have received relatively little scholarly attention. Researchers frequently rely on anecdotal evidence from newspapers and public health reports but do not systematically measure race-specific mortalities during the 1918 pandemic (Gamble 2010; Schlabach 2019). Earlier studies from the 1920s and 1930s use military statistics and local surveys to examine mortality patterns for specific sub-groups of the American population. In a comprehensive review of such studies, Økland and Mamelund (2019) find some evidence of a racial mortality crossover when the pandemic was most severe in the United States, during the fall of 1918: mortality rates may have been lower for Black people than for white people during those months, although it is not clear whether these findings are generalizable to the full U.S. population.

\footnotetext{
${ }^{1}$ The ratio of age-adjusted non-Hispanic Black to non-Hispanic white total mortality in 2019 was 1.18 ; in 2020, it was 1.34 (authors' calculations from Ahmad et al. [2021] and Centers for Disease Control and Prevention [n.d.]).
} 
The drivers of these patterns also remain unclear. Scholars have hypothesized that Black communities may have been disproportionately exposed to a less deadly "herald wave" in the spring of 1918 (Crosby 2003; Økland and Mamelund 2019), providing partial immunity against the deadlier fall wave. Segregation may also have functioned as an accidental cordon sanitaire that insulated nonwhite communities against infection (Schlabach 2019). Still, "shockingly sparse" data (Krishnan et al. 2020, p. 474) has thus far prevented the verification of such hypotheses (Gamble 2010).

In this study, we provide the first comprehensive descriptive analysis of racial disparities during the pandemic in U.S. cities. We also examine why these racial disparities were strongly reduced in the urban population. Integrating theories from demography, sociology, public health, and virology and immunology, and linking data from varied sources, we posit and assess four possible explanations. Two are linked to city-level characteristics like socio-demographic features and the implementation of non-pharmaceutical interventions (NPIs) like school closings, while the other two consider the life course histories of infectious disease exposure ("social immunology" [Shattuck 2021]) among urban white and nonwhite populations of this era. The first of these social immunology explanations, proposed in prior work (Crosby 2003; Økland and Mamelund 2019), suggests that mortality inequalities in 1918 may have been reduced because nonwhite populations were more likely to have had a prior influenza exposure (to a less severe "herald wave" of 1918's new H1N1 viral strain) that was protective. In contrast, the second suggests that disparities in 1918 may have been reduced because white populations were more likely to have had a prior influenza exposure (to an earlier pandemic peaking in 1890) that resulted in "immunological imprinting" that proved harmful when H1N1 pandemic influenza emerged.

We examine explanations related to city-level characteristics and social immunology using a combination of empirical tests and simulations. Our empirical tests combine data from multiple sources, including digitized mortality records for 70 U.S. cities; linked census records that establish urban residency status across multiple censuses; and a novel, comprehensive dataset on the timing of non-pharmaceutical interventions (NPI) - such as school shutdowns, mandatory closures of theaters and bars, and bans on public gatherings - collected from historical newspaper accounts. Simulations allow us to ascertain the plausibility of speculative explanations for which no direct measurements are available. To test the immunological imprinting explanation, for 
example, we employ a combination of five suggestive (but not definitive) empirical and simulation tests.

Consistent with prior work using different data (Gamble 2010; Krishnan et al. 2020; Økland and Mamelund 2019; Schlabach 2019), we find that racial disparities in pandemic mortality were almost uniformly reduced, compared to pre-pandemic years. Turning to potential explanations for these reductions, we find that city-level characteristics, like segregation and NPIs, fail to explain them. We also find little evidence that partial immunity due to herald wave exposure accounts for reduced racial disparities in pandemic mortality, although we speculate - based on qualitative accounts - that the 1918 herald wave may have induced relevant behavioral responses that protected Black communities during the peak months of the pandemic. This explanation merits exploration in future studies. The explanation we are unable to refute is the one based on immunological imprinting. We argue that the 1918 pandemic's reduced racial disparities may reflect a historical contingency, built on the interaction of the distinctive migration and public health experiences of nonwhite and white urban populations with the historical sequence of influenza strains that successively emerged between the late nineteenth century and 1918. This perspective on infectious disease mortality explicitly draws attention to the interplay between the macrosocial histories of differentially racialized groups and the microbiological characteristics of particular epidemics. While our research is rooted in the social and virological contingencies of the 1918 pandemic, this broader perspective is applicable to the study of racial inequality and unequal health outcomes during other public health emergencies.

\section{Potential Explanations for the Racial Gap in Influenza and Pneumonia Mortality in 1918}

The uniquely narrow racial mortality gap was widely recognized in 1918. Health officials in Chicago noted that race-specific incidence counts were "quite contrary to what would have been expected" (Schlabach 2019, p. 41), while a prominent Black reverend proclaimed that God had been trying "to show [the white man] the folly of the empty conceit of his vaunted race superiority, by dealing with him just as he dealt with the peoples of darker hue" (Bristow 1992, p. 73). Mortality tables constructed in the wake of the pandemic also noted unexpectedly high white mortality and reduced Black/white disparities in influenza mortality (Frankel and Dublin 1919). 
Two potential explanations have been proposed to account for these uniformly smaller mortality disparities, although neither has been tested systematically. The first focuses on local socio-demographic characteristics. Studies of health inequalities have repeatedly found that such characteristics can affect levels of infectious disease mortality, although the particular sociodemographic patterning of infections and the causal mechanisms driving it vary by disease and location (Bonds et al. 2010; Hart et al. 1998; Valleron et al. 2010; Waitzman and Smith 1998). Mortality in 1918 correlated with local illiteracy rates in Chicago (Grantz et al. 2016) and may have been elevated in communities that experienced living conditions conducive to the spread of infectious diseases due to factors like overcrowding (Mamelund 2018; Økland and Mamelund 2019). Residential segregation may also have offered temporary protection to nonwhite communities during the 1918 pandemic if it distanced groups, physically and socially, from centers of community transmission (Krishnan et al. 2020; Schlabach 2019). Moreover, some city characteristics that are associated with higher excess mortality in 1918, such as air pollution and illiteracy rates (Clay et al. 2019), may have had race-specific effects.

The second existing explanation focuses on the short-term immunological history of different racial groups. Although the overwhelming majority of 1918 influenza deaths occurred in the United States between September and December, a less lethal flu strain began circulating during an earlier "herald wave." Beginning between January and March, this wave led to a mortality increase in excess of normal seasonal mortality fluctuations (Hoffman 2011; Olson et al. 2005; Patterson and Pyle 1991); recent evidence suggests that this influenza strain subsequently evolved to evade immune responses, accounting for its radically increased lethality by September (Patrono et al. 2021). Crosby (2003, p. 229) has speculated that exposure to this herald wave may have primed the immune system for a more efficient response during the fall. Nonwhite communities may have disproportionately benefitted from such partial immunity because they were more likely than white communities to experience residential conditions that are conducive to the spread of infectious diseases, like overcrowding and lack of access to handwashing opportunities (Mamelund 2018; Økland and Mamelund 2019). In this scenario, partial immunity induced by the herald wave might explain the comparatively small mortality disparities during the fall because it made nonwhite individuals disproportionally resistant.

In addition to these existing hypotheses, we propose and evaluate two additional potential explanations based on recent work in historical and social immunology. First, we extend the 
literature on non-pharmaceutical interventions (NPIs). During the peak months of the 1918 pandemic, many American cities sought to contain the spread of infections by closing schools, theaters, and bars; banning gatherings in public places; and enforcing the quarantining of infected persons. Cities that implemented these NPIs early and sustained them until the end of the pandemic tended to experience lower weekly mortality peaks and lower overall mortality than cities that delayed NPIs or lifted them prematurely (Hatchett et al. 2007; Markel et al. 2007). ${ }^{2}$ Because nonwhite populations had a much higher baseline risk of infectious disease mortality, they may have disproportionately benefitted from NPIs. This hypothesis is analogous to Troesken's (2004) argument that water and sewage improvements in Southern cities disproportionately benefitted Black individuals due to their higher risk, absent such improvements, of waterborne disease. In this case, evidence in support of this explanation would show that cities with early NPI onset and long NPI duration experienced reduced nonwhite/white mortality ratios in addition to reduced total mortality.

We additionally propose and evaluate the novel explanation that immunological imprinting from a late $19^{\text {th }}$ century pandemic may account for reduced racial disparities in 1918 . We posit that the distinctive social and geographic histories of 1918's urban white and nonwhite populationsspecifically, the disproportionately rural origins of the urban nonwhite population-may have produced racial differences in early-life flu exposures that translated to increased immunological vulnerability, primarily for white young adults, during the 1918 pandemic. This explanation builds on existing work in historical immunology arguing that early childhood exposure to the pandemic beginning in 1889 may account for the unusually high mortality of young adults in 1918 (Gagnon et al. 2013, 2015; Hallman and Gagnon 2014; Luk et al. 2001; Mamelund 2011; Shanks and Brundage 2012; Woo 2019; Worobey et al. 2014, 2019). Extending this hypothesis to consider racialized life course exposures offers the enticing possibility of a consilience (Whewell 1858) between two of the most striking features of the 1918 pandemic: its unusual age shape and its

\footnotetext{
${ }^{2}$ One reason that NPIs were not sustained longer is that they were often highly controversial. As one Topeka, Kansas newspaper article put it in declaring the pandemic defeated in Topeka (after two flu-free days in April 1919): "Both [health commissioner] Porter and [health officer] Clark have been the target, during the last few months, for gobs of criticism and insubordination against what was termed the autocracy they were establishing in depriving the citizens of the privilege of freedom of action, the right to mingle with "flu' germs." ("Topeka Free of Flu" 1919) There was, however, context beyond the disruption associated with NPIs; Clark had been mocked by the same paper three weeks earlier for a snobbish declaration: "'How can you expect the common people to heed influenza warnings,' snorted Doctor Clark, 'when our socially best people sometimes show just as little sense about such things?”" (“Affair Riles Dr. H. L. Clark” 1919)
} 
reduced racial disparities. More broadly, it builds on the perspective that understands pandemics (such as the one that began in 1889) as events that reshape populations with long-lasting epidemiological consequences (Noymer 2010). (That previous pandemic reached U.S. port cities in December 1889; we will refer to it as the "1890 pandemic," reflecting its deadliest year. Its ending date is somewhat ambiguous.)

This imprinting explanation turns on current hypotheses about evolving Influenza A strains over the decades leading up to 1918. The 1918 flu was an H1N1 influenza; the leading hypothesis is that the 1890 pandemic was caused by an H3N8 influenza (Dowdle 2006). Because H1 and H3 hemagglutinin come from different phylogenic groups, their antibodies offer little cross-protection (Gostic et al. 2019), while first exposure to influenza within the same phylogenic group can offer long-lasting protection (Gostic et al. 2016). Work by virologists (Worobey et al. 2014) suggests that H3 may have remained in circulation until around 1900, when it was replaced by H1, producing a likely H1N8 outbreak in the early 1900s. The same virologists speculate that H1N8, or another influenza with HA similar to H1, predominated before the 1889 pandemic. Thus, people born around the time of the pandemic that began in 1889 would have been likely to have their earliest exposure to H3N8 influenza — with substantial phylogenic difference from 1918's H1N1— while those born much earlier or later would have been more likely to have early exposure to a homotypic influenza. We also explore a variant of this imprinting hypothesis in which exposure to the 1890 pandemic need not be one's first influenza exposure to result in imprinting during early childhood, via a mechanism called "immunological refocusing" (Gagnon et al. 2015); for our purposes, this means the key question is who had early childhood exposure to the 1890 pandemic, potentially irrespective of whether they were also exposed to an $\mathrm{H} 1$ influenza first.

According to the immunological imprinting explanation of elevated young adult mortality in 1918, the particular combination of antigenic similarities and differences between the 1890 and 1918 viruses may have led those whose immune systems had been "imprinted" through early exposure to the 1890 virus to respond to the 1918 virus with a dysregulated immune response characterized by an abundance of antibodies that could not neutralize that virus, crowded out a more effective immune response, and produced deadly tissue damage leaving them susceptible to secondary bacterial infections. By hypothesizing that such imprinting was more prevalent among 1918's urban white young adults than urban nonwhite young adults, we extend this possibility to potentially account for reduced racial disparities. 
Notably, the immunological imprinting explanation of reduced racial disparities explored here presumes that the 1890 pandemic was indeed caused by an H3N8 influenza virus. There are two clear alternative causative agents proposed: an H2N2 influenza virus (Mulder et al. 1958) and a coronavirus (Brüssow and Brüssow 2021; Vijgen et al. 2005, 2006). Since H2 is in the same phylogenic group as $\mathrm{H} 1$, it is not clear that immunological imprinting with $\mathrm{H} 2 \mathrm{~N} 2$ would have been as deeply deleterious in 1918 as this explanation requires; and should the 1890 pandemic turn out to stem from a coronavirus, the imprinting mechanisms just outlined would be moot. In either of these cases, childhood exposure to the 1890 pandemic presumably could account for vulnerability in 1918 only if it produced grievous bodily harm resulting in subsequent frailty.

Altogether, this leaves us with four potential explanations - two rooted in city-specific characteristics (Explanation A. segregation/illiteracy/density and Explanation B. NPIs) and two rooted in social immunology (Explanation $C$. protective immunity due to herald wave exposure and Explanation D. reduced immunity due to childhood imprinting). While the two potential explanations rooted in city-specific characteristics focus on local conditions during the 1918 pandemic, the explanations rooted in social immunology build on the distinctive social histories of exposure of each racial group prior to the pandemic. The urban white population of this era was a combination of recent immigrants from abroad, grown children of earlier immigrants, and some internal migrants, particularly through westward expansion. Yet many nonwhite urban residents had migrated only recently from rural Southern areas, where they experienced comparatively low exposure to influenza waves during childhood, to Southern and Northern cities where they were forced, by law and by violence, into intensely crowded, filthy, and dangerous conditions with very high exposure to infectious diseases (Ager et al. 2020; Økland and Mamelund 2019, p. 15; Roberts 2009). This combination of relatively low early-life exposure followed by intense exposure after urban migration allows for the mix of potentially protective and harmful exposures that we explore below.

\section{Data and Methods}

First, we integrate several data sources that allow us to examine racial mortality disparities across the United States, including a series of annual race-specific and cause-specific mortality rates for 70 American cities that is based on annual death counts collected by the Department of Commerce (Feigenbaum et al. 2019), supplementary datasets with age-specific and monthly mortality rates 
for a smaller number of cities ( $\mathrm{N}=20)$, and measures of an array of city characteristics and public health responses to the pandemic. All data sources are summarized in Table 1. Our mortality measure is based on death counts that were recorded as being due to either influenza or pneumonia, since pneumonia was the proximate cause of many deaths in the 1918 pandemic. We report disparities for alternative measures (total mortality and mortality due to influenza, pneumonia, and bronchitis) in the Appendix's section IB.

[Table 1 about here]

Historical Vital Statistics from the Department of Commerce report published death counts. The coverage of these mortality datasets includes cities from states that were included in the Death Registration Area (DRA) in 1918, as well as several additional large cities in states like Texas (which had not yet joined the DRA but reported death counts for specific cities). Race-specific death counts were collected only in cities that had at least 10\% nonwhite population in the 1910 Census; accordingly, we do not capture the population living in cities that were nearly exclusively white. While our primary dataset with annual race-specific mortality rates includes large and medium-sized cities across the United States, monthly race- and age-specific mortality estimates are only available for a reduced number of large cities. The smallest city included in our supplementary, monthly data is Nashville, TN, with an estimated 126,000 residents in 1918. Our findings may not extend to smaller cities or non-urban settings.

To convert these death counts into death rates, we estimate race-specific, age-specific populations for each city. Because the 1920 Census likely reflected substantial population distortions resulting from the pandemic — due to the high number of deaths in 1918, the unusual W-shaped mortality pattern during the pandemic, and its close proximity to the 1920 Census count -we avoid drawing on that Census in constructing our population denominators. Instead, our main measure interpolates populations (on log scale) from 1910 to 1930. We include alternative mortality calculations that draw on 1920 data in the Appendix. Since our main measure may be distorted by altered migration patterns in the 1920s compared to the 1910s, we also construct an alternative denominator by estimating population sizes from non-infectious death counts, which were reported annually. To avoid pandemic-related distortions, such as those from social distancing and competing risks, we predict 1918 non-infectious death counts from the prior three years. (Details of this alternative measure are reported in the Appendix's section IC.) These two mortality measures, which make very different assumptions when estimating 1918 population 
counts, evince relatively close agreement: for example, the alternative measure estimates the nonwhite/white ratio of flu and pneumonia mortality at 1.39 in 1918 (vs. 1.35 with our main measure) and 2.41 in 1910-1917 (vs. 2.33).

The Vital Statistics report deaths in "White" and "Colored" populations. In this era, the latter (nonwhite) populations in cities were overwhelmingly Black, and we interpret them as a measure of Black mortality. We measure disparities in a multiplicative scale, using the ratio of nonwhite to white mortality in descriptive results and estimating regressions in logit scale. Our unit of analysis is cities.

Next, we assess our four possible explanations for the racial mortality gap in 1918: A. citylevel segregation, illiteracy, and residential density; B. city-level NPIs; C. partial immunity from spring 1918 "herald wave"; D. immunological imprinting. To explore the first two explanations, we combine mortality data with a wide array of city- and race-specific measures of segregation, residential density, illiteracy, air pollution, age composition, and the onset and duration of NPIs. We collected NPI data from a qualitative survey of historical newspaper records. Specifically, we recorded the number of total days that mandatory quarantine, bans on public gatherings - which included the closure of theaters, bars, and restaurants - and school closings were in effect. We did not count NPIs implemented only in military camps, since those camps were commonly located beyond city limits and administered by the U.S. military rather than municipal authorities. Following Markel et al. (2007), we calculated total NPI duration by summing across all NPI types. We find a high correlation $(r=0.9)$ between our original NPI measures and those obtained by Markel et al. (2007) for cities appearing in both datasets. We also measured the number of days between the first locally recorded infection and the start of NPIs, which we treat as a measure of NPI delay. In total, we were able to expand Markel et al.'s (2007) dataset on the date and duration of school closings and bans on public gatherings from 43 cities to 52 cities; 34 of those 52 cities reported race-specific death counts in the Vital Statistics and are included in our analyses.

City-specific calculations of segregation indices and measures of city- and race-specific illiteracy rates and residential density are based on census microdata via IPUMS (Ruggles et al. 2020), while additional variables that capture other city-level variables are taken from several prior studies (Clay et al. 2019; Collins et al. 1930; Crosby 2003; Markel et al. 2007), as summarized in Table 1. We use full-count census data to calculate illiteracy rates and four separate indices of segregation: the dissimilarity index (White 1983), the divergence index (Reardon and O'Sullivan 
2004), the variance ratio index (Roberto 2016), and the sequence index of segregation (Grigoryeva and Ruef 2015). We use the $1 \%$ census sample to construct indices of residential density based on the average number of persons per dwelling and the percentage of residents living in multifamily homes. We use the $1 \%$ sample rather than the full count because the required variables are not reliable in the current iteration of the IPUMS-USA full-count data (Ager et al. 2020).

We use these data to construct a series of bivariate and multivariate models that specifically test the predictions of each hypothesis and control for variables like age composition and NPI implementation, which are known to have affected infectious disease mortality in the United States in 1918. Specifically, we construct multivariate linear models that regress logged mortality ratios on city- and race-specific measurements of illiteracy and residential density and city-specific racial segregation indices, controlling for logged baseline mortality that captures potential unobserved time-invariant confounders (predicted from 1910-1917 trends for each city), local age composition (measured as the percentage of residents aged 20-39), and local non-pharmaceutical interventions (NPIs). Likewise, to assess the association between race-specific mortality and NPIs, we construct a series of linear models that regress logged race-specific mortalities and logged mortality ratios on NPI duration, NPI delay, and race-specific baseline mortalities and baseline mortality ratios for each city. Full details on these models (including regression equations) are reported in the Appendix's section II; power calculations for all models are reported in the Appendix's section IIE. Models are generally well-powered with the exception of the analysis of the "herald wave"; we discuss this limitation when we report those results, below.

We test the partial immunity hypothesis, which posits that racial differences in exposure to the milder spring 1918 "herald wave" contributed to mortality patterns during the deadlier fall wave, by answering two questions: First, were nonwhite populations more affected by the herald wave than white populations? Second, was greater exposure to the herald wave associated with reduced mortality during the fall wave? These analyses use influenza and pneumonia mortality during January-June 1918 as a proxy for population-level partial immunity during SeptemberDecember 1918. Because this proxy measure assumes equal infection fatality across racial groups and cities, it is highly imperfect, made necessary by the almost total lack of historical data on race-specific influenza exposure rates. To our knowledge, such data were only collected during the peak of the 1918 pandemic (rather than the spring) from non-random samples in six U.S. cities and in several military camps (Britten 1932; Frost 1920; Ireland 1929). The 
generalizability of these surveys is severely limited, yet they indicate that, during fall 1918, Black populations may have experienced a $\sim 30 \%$ higher infection fatality rate compared to white populations, and that race-specific exposure rates may have been as low as $5 \%$ and as high as $50 \%$. These data suggest that the bias in our proxy measurement for spring exposure may lead us to over-estimate the prevalence of herald wave infections in nonwhite communities, and thereby also over-estimate racial differences in herald wave exposure - the key purported reason for race-specific differences in immunity. We discuss the consequences of this potential bias, and more broadly of potential noise, in this measure when we present the herald wave results, below.

To test the immunological imprinting explanation (for which no direct measurements are available), we use a rough empirical proxy for variation in childhood exposure to the 1890 pandemic: 1918 urban populations' urban origins, estimated from the Census Linking Project (Abramitszky et al. 2020; Abramitzky et al. 2021), working from the assumption that urban children would have had greater influenza exposure than rural children in 1890. We also develop a set of simple simulations that evaluate the effects of 1890 flu exposure on the magnitude of agespecific mortality in 1918, exploiting cohort variation in the likelihood of the 1890 pandemic being individuals' first flu exposure. These simulations allow us to answer two questions. First, how high would mortality need to be among individuals who were "imprinted" with the H3N8 virus during childhood to generate age- and race-specific mortality rates that we observe in 1918? Second, what exposure rates to the $1890 \mathrm{flu}$ (and prior influenza strains) would be required to produce these imprinting rates? We assess the plausibility of the resulting parameter ranges consistent with the imprinting explanation by comparing them to empirical data obtained in other immunological studies. In particular, we focus on assessing the plausibility of the parameter ranges for 1918's urban white young adults - the key population driving reduced aggregate disparities. This twopronged empirical and simulation-based methodological approach allows us to narrow the space of plausible explanations despite the scarcity of historical health data (particularly from the nineteenth century). The immunological imprinting tests are explained in further detail in the section on the imprinting analysis, below.

Details of all data sources, measures, statistical models, and simulations are given in the Appendix. Data, codebook, and software code are available at http://doi.org/10.17605/OSF.IO/NJGHD. 


\section{Descriptive Results: Nonwhite and White Influenza and Pneumonia Mortality in 1918}

The 1918 pandemic occurred in the context of extreme, ubiquitous racial inequality in the United States-including inequality in infectious disease mortality. Prior to 1918, nonwhite residents across U.S. cities (who were overwhelmingly Black during this period) were more than twice as likely to die from influenza and pneumonia as white residents. Nonwhite populations still experienced some of the highest recorded mortality rates during the 1918 pandemic, but the nonwhite/white inequality in influenza mortality was around three-fourths smaller than in previous years; we find the median city's nonwhite/white mortality ratio was 1.35 in 1918, compared with 2.33 over the pooled years 1910-1917. Equally striking is the small variation in influenza and pneumonia mortality disparities across cities (Figure 1). The 1910-1917 median standard deviation in nonwhite/white mortality ratios across 70 cities was 1.11 , yet it shrank to 0.32 in 1918 . This is unexpected, considering which subpopulations were represented in age groups most at risk during the pandemic: the very young, the very old, and young adults. White people were over-represented among the very young and old, but nonwhite people where over-represented among young adults who had fairly high mortality rates.

[Figure 1 about here]

This sudden decline in the mortality ratio reflects the fact that, on average, nonwhite flu deaths in 1918 were around three times the pre-pandemic average-while white flu deaths were five times the pre-pandemic average. Young adults aged 10-39 experienced the largest proportional mortality increase. Figure 2 shows that average nonwhite influenza and pneumonia mortality among those aged 10-39 grew from 156 deaths per 100,000 people in pre-pandemic years to 732 deaths in 1918, and average white mortality increased from 42 deaths per 100,000 people to 627 deaths. In the group with the highest excess mortality during the 1918 pandemic — whites aged 20-29 - mortality was almost 20 times higher in 1918 than in the pooled 1910-1917 years.

The narrowing of racial disparities in mortality was largely due to a mortality convergence among those aged 10-19, 20-29, and 30-39 (Figure 2). These three groups had the highest prepandemic disparities - with the nonwhite/white influenza and pneumonia mortality ratios measuring 4.48, 4.15 and 3.39 respectively_but had among the smallest disparities in 1918. Disparities were notably nonexistent in the 20-29 and 30-39 age groups. Compared to 1910-1917, 
nonwhite/white flu and pneumonia mortality disparities in 1918 declined by 78 percent in the 1019 age group, by 95 percent in the 20-29 age group, and by 98 percent in the 30-39 age group.

[Figure 2 about here]

In contrast, racial disparities in influenza and pneumonia mortality among the very young and the very old were considerably less affected by the pandemic. At ages 70+, nonwhite mortality was (and remained) roughly comparable to white mortality. This low inequality likely reflected the operation of selective mortality at younger ages (Vaupel and Yashin 1985), given the high nonwhite mortality rates of this era. And among children aged 0-9, nonwhite mortality was (and remained) higher than white mortality. Nonwhite children experienced a median of 890 influenza and pneumonia deaths per 100,000 during the pooled 1910-1917 years and a median 1571 deaths per 100,000 in 1918, compared to a pre-pandemic median of 268 deaths and a pandemic median of 608 deaths for white children. Because of the high mortality among these younger ages, most of the absolute difference between nonwhite and white death counts in 1918 can be traced to differences among children aged 0-9 (Figure 2).

\section{Results: Potential Explanations for Reduced Disparities in 1918}

A summary of findings from the suggestive tests conducted for each of the possible explanations for reduced racial disparities in 1918 urban pandemic mortality is in Table 2. We now describe the results pertaining to each of these explanations in turn.

[Table 2 about here]

\section{Explanation A. Segregation, illiteracy, residential density}

We assess the link between socio-demographic indicators and mortality patterns by testing whether levels of residential segregation and nonwhite/white ratios of residential density and illiteracy were associated with nonwhite/white mortality ratios in 1918. We expect that more highly segregated cities and cities with smaller racial disparities in illiteracy and residential density experienced smaller racial disparity in influenza and pneumonia mortality.

We observe that the race-specific baseline mortality - that is, the expected mortality in a city in 1918, given its mortality trends in the years 1910-1917-was a strong predictor of 1918 observed mortality. This suggests that communities that were generally vulnerable to infectious diseases remained so during the pandemic. But we find no evidence that segregation, illiteracy rates, or residential density were associated with racial disparities during the pandemic (Table S1 
in the Appendix). Our socio-demographic predictors from 1918 were also statistically indistinguishable from coefficients from non-pandemic years between 1910 and 1930. Although city characteristics and socio-demographic indicators may explain general infectious disease mortality rates during the early twentieth century, our findings suggest that they are insufficient to explain the specific mortality patterns and mortality disparities of the 1918 pandemic.

These findings are robust to the substitution of alternative segregation and density indices into our models and to the use of logged race-specific mortality and excess mortality rather than logged mortality ratios as the dependent variable. In an additional model, we also include a measure of local coal-fired powerplant capacity as a proxy for air pollution, which has been found to be predictive of 1918 influenza mortality in an earlier study (Clay et al. 2019). This also does not predict 1918 nonwhite/white disparities.

\section{Explanation B. Non-pharmaceutical interventions (NPIS)}

Similar to prior studies that use weekly mortality data (Hatchett et al. 2007; Markel et al. 2007), we find evidence that early NPI onset-i.e. a shorter delay between the first locally reported infection and the implementation of NPI measures - was associated with lower annual nonwhite mortality. For white populations, we observe a similarly positive but statistically insignificant association between NPI delay and annual mortality. At first glance these findings may suggest a slight but potentially disproportionate impact of NPIs on nonwhite mortality. Yet we find no statistically significant effect of NPI onset or NPI duration on nonwhite/white mortality ratios, and no evidence that coefficients for the association between NPIs and mortality were significantly different for nonwhite and white populations (Figure 3; Appendix Table S2). These null findings are robust to different model specifications and to the substitution of NPI data from other sources (Hatchett et al. 2007; Markel et al. 2007) for our original measures. It therefore appears unlikely that the reduced mortality disparities during the 1918 pandemic were due to pronounced racially disparate impacts of ostensibly race-neutral measures like NPIs.

[Figure 3 about here]

\section{Explanation C. Partial immunity}

We test the partial immunity explanation by answering two questions: 
Question C1: Were nonwhite communities more affected by the herald wave than white communities? Cities that experienced high influenza mortality during the 1910-1917 period were also more likely to experience high mortality during the 1918 spring wave. Alongside this cityspecific mortality penalty, nonwhite populations experienced a more severe spring wave than white populations (Figure 4). Compared to the period 1910-1917, median nonwhite mortality increased by $50 \%$ while median white mortality increased by $30 \%$. As a result, the median nonwhite/white mortality ratio in the spring of 1918 was 2.79 , compared to 2.43 during the pooled period 1910-1917. This made the spring of 1918 among the most unequal periods recorded in our pre-pandemic data, tying mortality disparities observed during the 1912 spring wave and exceeding disparities during the (least unequal) 1915 spring wave by $42 \%$.

[Figure 4 about here]

Question C2: Across cities, was greater exposure to the herald wave associated with lower mortality during the deadlier fall wave? We predict a race-independent negative spring/fall association, since populations that experienced greater mortality in the spring should be partially immune to the pandemic viral strain and therefore experience lower mortality during the fall. Yet we find the association between spring and fall mortality to be indistinguishable from zero for nonwhite populations and either indistinguishable from zero or positive for white populations, depending on the control variables included in the model (Figure 4). This null finding is robust to changes in the dependent variable, e.g. using mortality ratios rather than race-specific mortality and using spring/fall mortality data published in the appendix to (Crosby 2003); to a substitution of NPI data taken from Markel et al. (2007) for our original data; to different specifications of the herald wave's duration; and to a stratification of our model into multiple tiers of herald wave severity (all results in Appendix Table S4).

These findings make it unlikely that mortality disparities during the pandemic can be explained by greater partial immunity among the nonwhite population as a result of herald wave exposure. Although we are able to examine the association between spring exposure and fall mortality more systematically than prior studies, our analysis has two major limitations. First, the relatively small number of cities included in the sample limits the statistical power of our models. The power of models that test the association between spring wave exposure and fall mortality ranges from 0.21 to 0.62 : well below a conventional threshold of 0.8 . This means that we would be able to distinguish only large effects, and it leads us to treat our null finding as merely suggestive 
evidence that needs to be corroborated through future historical work. Second, if infection fatality rates were higher in nonwhite populations, then excess deaths among those populations should imply fewer infections than the same excess deaths in white populations. The exposure inferred from mortality would then be erroneously high for nonwhite populations vs. white, and our estimates of nonwhite/white disparities in herald wave exposure would be upwardly biased.

The potential bias in overstating exposure disparities would lead us to overstate one key premise of the herald wave hypothesis ( $\mathrm{C} 1$ in Table 2), but the potential noisiness could contribute to disguising a clear signal of the other key premise, namely, a race-independent negative association between spring exposure and fall mortality ( $\mathrm{C} 2$ in Table 2). Given that such an association is essential to the partial immunity hypothesis, the potential overstatement of nonwhite/white exposure disparities is a less acute limitation than the models' low statistical power and potential cross-city measurement error. Perhaps the best summary of the total state of evidence that can be given is that, at the end of our analysis, it remains the case that-across all literature on the 1918 pandemic - there is no clear empirical evidence for the herald wave hypothesis.

We are also unable to determine whether statistically significant differences between nonwhite and white spring/fall mortality associations are artifacts of our models or hint at potential race-specific effects of herald wave exposure. Such race-specific effects would lend themselves to multiple possible interpretations, particularly in light of the lack of common support visible in Figure 4: the distributions of spring wave mortality in white and nonwhite urban populations barely overlap. It is possible that immunity mechanisms operate within a restricted range at the population level that is only discernible in nonwhite populations, given their substantially greater exposure during the spring wave. Alternatively, potentially race-specific effects of herald wave exposure may reflect behavioral, rather than immunological, responses. Because the regular hospital system often refused to admit African-Americans or triaged them into sub-standard care, public health campaigns in nonwhite communities relied more heavily on community-based prevention and education (Gamble 2010; Krishnan et al. 2020; Schlabach 2019). Those initiatives, as well as the persistent experience of high infectious disease mortality, may have contributed to greater lay knowledge about infectious diseases in urban nonwhite communities (Økland and Mamelund 2019 , p. 13) and precipitated greater vigilance during the pandemic even as mainstream newspapers initially played down the severity of infections (Crosby 2003). 


\section{Explanation D. Immunological imprinting}

No direct measure of exposure to the 1890 influenza virus is available, so as an alternative, we conduct suggestive tests of five predictions (summarized in Table 2) based on necessary conditions for the hypothesis that immunological imprinting explains reduced 1918 disparities (outlined in Table 3). We evaluate these claims in turn, using a mixture of empirical and simulation analyses.

[Table 3 about here]

Analysis D1. Impact of young adults on mortality disparities: We find that the reduced disparities in 1918 were driven by the age bands that would have been most likely to have first flu exposure to the 1890 pandemic strain (Figure 5): reduced disparities reflect strikingly high mortality among urban whites in their 20s and 30s (as already shown in Figure 2). A counterfactual estimate of mortality disparities suggests that up to three-fourths of the decline in mortality disparities in 1918 (compared to the 1910-1917 period) was due to reduced disparities among those aged 20-29 and 30-39 (details in Appendix section IIIA).

[Figure 5 about here]

The key role of these two age groups is consistent with the hypothesis that immunological imprinting accounts for reduced racial disparities. However, that hypothesis seemingly leaves the relatively small disparities at ages 10-19 — while not as small in absolute terms or relative to prepandemic values as the 20-29 and 30-39 age groups - as an anomaly. Yet, from a broader perspective in which deleterious imprinting works hand in hand with helpful H1 exposures (Worobey et al. 2014, pp. 8110-8111), this age group may be less anomalous: they may have been likely candidates for $\mathrm{H} 1$ exposure in the years before the 1918 pandemic, particularly for nonwhite children living in appallingly poor urban conditions. Urban white children and teenagers may have been more likely to be fully immunologically naive to H1N1.

Analysis D2. Differential 1890 exposure: Since no direct measure of exposure to the 1890 virus is available, we use urban residency during childhood and adolescence as a proxy for 1890 flu exposure, given greater infectious disease prevalence in urban compared to rural areas (Feigenbaum et al. 2020). We find that such urban origins were more prevalent among the 1918 urban white population than among the 1918 urban nonwhite population (Condition 2a in Table 3; see discussion of alternative Condition $2 b$ in the Appendix's section IIIA). Specifically, among cohorts aged 20-39 in 1918 and residing in cities in 1910, we estimated the national proportion 
with long-term urban residency at nearly half of the nonwhite population compared to nearly twothirds of the white population. We estimated the proportion with long-term residence in cities of at least 100,000 residents (whose influenza exposure may have been heightened [Feigenbaum et al. 2020]) at around one-fifth of non-white and more than one-third of white residents. Thus, we find that it is indeed plausible that urban white young adults in 1918 may have had higher childhood exposure to the 1890 pandemic than urban nonwhite young adults in 1918 did, due to the white young adults' greater chances of having spent childhood in a city. Because these calculations require the linking of individuals across multiple censuses, they include considerable uncertainty due to the small percentage of linkable persons; we discuss this limitation, and other choices made in constructing this measure, in the Appendix's section IIIA.

Analysis D3. Effect of 1890 exposure on mortality in 1918: We find that cities with a larger proportion of longtime urban residents had higher 1918 mortality. Specifically, we tested whether the estimated city-level variation in the portion of the total, white, and nonwhite populations with urban origins was associated with greater 1918 mortality in total and in the 20-29 and 30-39 age groups, with and without controls for NPI timing and duration. This association is in the expected direction (i.e., more residents with urban background is associated with greater mortality) in all models. We also find that having a higher proportion of residents with urban origins is associated with reduced nonwhite/white mortality ratios, although the coefficient becomes statistically insignificant when we control for NPIs (full regression results are reported in Table S5 in the Appendix). Given the small samples and imprecise measures, we consider these results to be broadly suggestive but hardly definitive.

Analysis D4. Simulated individual-level effect sizes: To evaluate whether the imprinting explanation rests on plausible assumptions about the prevalence and consequences of imprinting, we simulate cohort mixtures of imprinted and non-imprinted individuals. We find that the imprinting explanation need not require imprinting prevalence or individual-level effects (Conditions $4 \mathrm{a}$ and $4 \mathrm{~b}$ in Table 3 ) that are clearly implausible. Specifically, our simulations answer two questions. First, how high would the mortality of the imprinted individuals need to be, as a function of the imprinted percentage in each cohort, to generate the observed age-group-specific, race-specific mortality rates? Assuming an upper limit on "reasonable" mortality rates imposes a lower limit on what portion of this age group must have been imprinted. When combined with assumptions about how many cohorts were partially imprinted, this also generates lower limits on 
within-cohort imprinting. These lower bounds on the portion of a birth cohort that would need to be imprinted can be evaluated for plausibility. Second, what rates of exposure to previous flus could generate these cohort imprinting rates? High rates of imprinting imply high rates of 1890 pandemic exposure and either low rates of prior H1N8 exposure (i.e., the seasonal flu variants circulating before 1890) or high rates of immunological refocusing, all of which can likewise be evaluated for plausibility. The simulated answers to this second question, in particular, are exploratory. Our goal is not to provide any definitive evaluation of these immunological hypotheses (with and without immunological refocusing) as an explanation of 1918's reduced racial disparities, but rather, by clarifying their implications, to construct a foundation that would allow them to be evaluated in future historical virological work.

To address the first question, we first leverage the sharper age cutoff in the 20-29 age group: individuals who were younger than 25 in 1918 were too young to have been exposed to the "Russian" flu, without antibodies developed in utero or while breastfeeding, in 1890-1893 (using 1893 as a generous cutoff date for the pandemic). Given the immense aggregate 1918 mortality in the 20-29 age group, we estimate that this restriction implies very large individual-level imprinting effects indeed: to fully account for the greater aggregate mortality in this age group compared to others, 1890 imprinting would need to increase individual-level mortality by a factor of at least 1.9 in nonwhite populations and 3.75 in white populations. Constraining the individual-level effect to be on the smaller end of the range of effect sizes essentially implies that the cohorts aged 25-29 had close to universal 1890 imprinting among urban white individuals. For example, urban white people aged 25-29 who were imprinted by the 1890 virus in childhood would have to have had greater mortality than urban white people aged $70+$ in 1918 , unless at least $85 \%$ of urban whites in the 25-29-year-old cohorts had been imprinted (Figure S2 in the Appendix; details, including equations, in Appendix section IIIBi). (It is also possible that immunological imprinting occurred for a smaller subset of these cohorts alongside some other source of high young adult mortality that also disproportionately affected white urban populations.) For comparison, serological evidence from the Netherlands (not from a specifically urban population) found that about half of the 1893 birth cohort showed evidence of early H3 imprinting (Dowdle 1999).

Since the mortality jump among those aged 20-39, compared with surrounding age groups, is smaller in the nonwhite population, this same constraint is compatible with a far greater range of 1890 cohort imprinting, ranging below $60 \%$. To the extent that the urban white population's 
greater likelihood of urban childhood corresponds to a higher prevalence of imprinting, the smaller mortality increase for nonwhite compared to white young adults is compatible with these differences in origin.

Analysis D5. Historical plausibility of estimated imprinting rates: To provide some rough, exploratory calibration of the individual-level flu attack rates implied by these cohort exposures, we simulated annual rates of childhood exposure to H1 strains before 1890, rates of exposure to an H3N8 influenza in 1890-92 for urban and rural populations, and rates (including 0\%) of immunological refocusing conditional on exposure to H3N8 after exposure to an $\mathrm{H} 1$ strain. These simulations suggest that, for immunological imprinting to account for the dramatic spike in urban white young adult mortality, either the rate of exposure during the 1890-1892 pandemic or the rate of immunological refocusing given exposure in that pandemic must have been very high (Figure S3 in the Appendix; details, including equations, in Appendix section IIIBii) - though not outside the boundaries of the attack rates estimated for the $1890 \mathrm{flu}$ (Valleron et al. 2010), or for pandemic influenza attack rates generally (Mathews et al. 2009, p. 147; Saunders-Hastings and Krewski 2016, p. 7).

\section{Conclusion}

Analyses of city-level mortality data suggest that racial disparities during the 1918 pandemic were uniformly small across cities. The excess mortality for nonwhite, compared to white, populations shrank $74 \%$ (from $133 \%$ to $35 \%$ excess), driven primarily by unusually high mortality among whites aged 20-39. These findings are surprising for several reasons. During the early twentieth century, racial disparities in infectious disease mortality were staggeringly large. The risk of death from infectious disease among nonwhite people in the U.S. in this era was so high that it explains much of the observed regional variation in urban infectious mortality during the first decades of the twentieth century (Feigenbaum et al. 2019). Public health responses to the pandemic were also steeped in racism and routinely provided sub-standard care to nonwhite communities (Bristow 1992; Byrd and Clayton 2001).

In 1918, public health officials attempted to explain reduced mortality disparities with racial pseudo-science that cast nonwhite populations as naturally immune to infectious diseases (Schlabach 2019). Subsequent scholarly works take a very different perspective and focus on racespecific immunological histories and the spatial geography of urban life in the early twentieth 
century (Crosby 2003; Grantz et al. 2016; Krishnan et al. 2020; Økland and Mamelund 2019), although none test these hypotheses systematically. In this study, we are able to leverage racespecific mortality data and a host of city-level characteristics for up to 70 cities to examine plausible explanations. Our findings do not provide support for two of the most frequently cited hypotheses - disproportionate partial immunity in nonwhite communities as a result of higher exposure to a spring herald wave, and reduced exposure as a result of residential segregationsuggesting that these hypotheses likely do not explain city-level disparities during the pandemic. In particular, prior studies (Crosby 2003; Økland and Mamelund 2019) have proposed the herald wave hypothesis as a plausible, but empirically unsubstantiated, explanation for reduced racial disparities during the fall pandemic. We test it more systematically than prior studies and find no evidence to support it. However, limitations due to scarce historical data prevent us from conclusively rejecting the hypothesis; these partial immunity results are merely suggestive due to the limited statistical power of our models. We also do not find support for the hypothesis that non-pharmaceutical interventions such as school closings, which have been shown to reduce overall mortality (Hatchett et al. 2007; Markel et al. 2007), explain reduced mortality disparities.

Instead, our findings produce a diverse, albeit merely suggestive, set of evidence suggesting that the unique migration and public health histories of nonwhite and white populations may have intersected with the virology of the 1918 influenza strain to produce especially high excess mortality (relative to pre-pandemic years) among whites between the ages of 20 and 39, thereby contributing to the unexpectedly reduced mortality disparities. This explanation draws on the idea that "immunological imprinting" to the 1890 influenza pandemic in early childhood may have driven immunological responses to the 1918 pandemic, nearly three decades later (Gagnon et al. 2013; Worobey et al. 2014). We hypothesize that the disproportionately urban origins of urban white young adults in 1918, compared to urban nonwhite young adults who had disproportionately migrated from rural areas, may have resulted in differential exposure to the 1890 flu pandemic during critical childhood developmental windows and produced a unique racial patterning of vulnerability in 1918. We attempt to refute this novel explanation for reduced racial disparities in five distinct empirical and simulation analyses; all five instead produce results broadly compatible with the explanation, though suggesting that it would need to be operating nearly universally in key cohorts to fully account for the distinctively high white young adult mortality. 
More broadly, these results establish that, given these distinctive exposure histories among different racial groups in 1918, racial patterns of mortality can be used to develop and evaluate hypotheses in historical virology, just as the unique age pattern of 1918 mortality has been. Some of the specific analyses reported here will likely be obviated if future virological work confirms the still-speculative hypothesis that the 1890 pandemic was caused by a coronavirus (Brüssow and Brüssow 2021; Vijgen et al. 2005, 2006) rather than an H3N8 influenza (Dowdle 2006; Worobey et al. 2014); in that case, patterns of prior H1 influenza exposure will remain relevant to outcomes in 1918 but patterns of exposure to the 1890 pandemic may not, unless their mechanism is not immunological imprinting but rather long-term morbidity stemming from childhood exposure to the coronavirus.

Our analyses also leave room for competing hypotheses to be resuscitated or adapted, especially since infectious disease mortality is generally overdetermined by a combination of multiple social and immunological factors. For example, nonwhite communities may have experienced comparatively low excess mortality as a result of behavioral adjustments - rather than partial immunity - following the spring herald wave, reducing their exposure to infectious disease agents in the fall of 1918. Excluded from the regular public health system but accustomed to high infectious disease mortality, nonwhite populations regularly relied on community-based education and prevention to reduce infections and may have been more circumspect during the pandemic's peak (Krishnan et al. 2020; Schlabach 2019). While our data do not allow us to test this hypothesis directly, our (underpowered) findings of a possible race-specific association between prepandemic exposure and pandemic mortality offer suggestive support to explanations that highlight such behavioral pathways.

Alongside our specific findings, an additional contribution of this work is that it offers a framework for analyzing racial disparities in infectious disease mortality that is widely applicable to a variety of periods, contexts, and microbes. We treat racial categories as socially constructed proxies for group-specific social histories that reflect broader structures of inequality, including structural racism, not as ready-made biological or demographic facts. The mortality signature observed in the 1918 pandemic results from the interaction of a particular microbe with those racialized social histories of exposure. Understanding the patterns and drivers of inequality in infectious disease mortality therefore requires examining how structural and institutions arrangements shape social and microbial exposures over time. 
Perhaps most importantly, simplistic comparisons between 2020, 2021 or 2022 and 1918 are misguided because the specific virology of COVID-19 and the historically rooted vulnerabilities of different social and racialized groups differ from those of the early twentieth century. It is notable that mortality at the peak of the 1918 pandemic was substantially higher than monthly mortality rates recorded during the COVID-19 pandemic (Weinberger et al. 2020). More generally, while racial disparities are generally conditioned by contexts of structural racism, their proximate causes may differ across pandemics. For example, in the 1918 pandemic, Black populations had lower morbidity but higher case fatality (Krishnan et al. 2020; Økland and Mamelund 2019), but studies of the COVID-19 pandemic return ambiguous results about the relative importance of exposure and immunological susceptibility (Navar et al. 2021; Ogedegbe et al. 2020; Rentsch et al. 2020; Zelner et al. 2021). The details of one pandemic's course cannot be imported wholesale to understand another. But applicable to a variety of contexts, historical periods, and infectious exposures is the broader framework of attending to the intersection between the natural history of a microbe and the social histories of the populations that are exposed to it. 


\section{Tables}

\begin{tabular}{|c|c|c|c|c|}
\hline Variables & $\mathbf{N}$ (Cities) & $\begin{array}{l}\text { Years } \\
\text { covered }\end{array}$ & Comment & Source \\
\hline $\begin{array}{l}\text { Annual mortality, } \\
\text { cause- and race- } \\
\text { specific }\end{array}$ & 70 & $1900-1930$ & $\begin{array}{l}\text { Limited to states and cities that } \\
\text { were included in the Death } \\
\text { Registration Area in 1918; } \\
\text { pre-1918 data are missing for } \\
\text { some cities }\end{array}$ & $\begin{array}{l}\text { U.S. Department of } \\
\text { Commerce/ Digitized by } \\
\text { research team }\end{array}$ \\
\hline $\begin{array}{l}\text { Annual mortality, } \\
\text { cause-, race- and } \\
\text { age-specific }\end{array}$ & 20 & $1900-1930$ & $\begin{array}{l}\text { Limited to states and cities that } \\
\text { were included in the Death } \\
\text { Registration Area in 1918; } \\
\text { pre-1918 data are missing for } \\
\text { some cities }\end{array}$ & $\begin{array}{l}\text { U.S. Department of } \\
\text { Commerce/ Digitized by } \\
\text { research team }\end{array}$ \\
\hline $\begin{array}{l}\text { Monthly mortality, } \\
\text { cause- and race- } \\
\text { specific }\end{array}$ & 20 & $1900-1930$ & $\begin{array}{l}\text { Limited to states and cities that } \\
\text { were included in the Death } \\
\text { Registration Area in 1918; } \\
\text { pre-1918 data are missing for } \\
\text { some cities }\end{array}$ & $\begin{array}{l}\text { U.S. Department of } \\
\text { Commerce/ Digitized by } \\
\text { research team }\end{array}$ \\
\hline $\begin{array}{l}\text { Population counts, } \\
\text { cause- and race- } \\
\text { specific }\end{array}$ & 1205 & $1900-1930$ & $\begin{array}{l}\text { Log-interpolated values for } \\
\text { intercensal years based on } \\
1910 \text { and } 1930 \text { census counts }\end{array}$ & $\begin{array}{l}\text { U.S. Department of } \\
\text { Commerce/ IPUMS }\end{array}$ \\
\hline $\begin{array}{l}\text { City characteristics, } \\
\text { including } \\
\text { residential density, } \\
\text { residential } \\
\text { segregation, } \\
\text { illiteracy rates, and } \\
\text { share of foreign- } \\
\text { born residents }\end{array}$ & Up to 881 & $1900-1930$ & $\begin{array}{l}\text { Density measures are } \\
\text { estimated on the basis of } 1 \% \\
\text { census samples; number of } \\
\text { cities in the dataset varies } \\
\text { between } 329 \text { (for residential } \\
\text { density estimates) and } 881 \text { (for } \\
\text { residential segregation indices) }\end{array}$ & $\begin{array}{l}\text { U.S. Department of } \\
\text { Commerce/ IPUMS }\end{array}$ \\
\hline $\begin{array}{l}\text { Childhood urban } \\
\text { residency rates, } \\
\text { race-specific }\end{array}$ & 601 & $1900-1910$ & $\begin{array}{l}\text { Low percentage of linked } \\
\text { census records may distort } \\
\text { estimated rates }\end{array}$ & $\begin{array}{l}\text { Census Linking Project/ } \\
\text { IPUMS }\end{array}$ \\
\hline NPIs & 52 & 1918-1919 & & $\begin{array}{l}\text { Original data collection } \\
\text { through newspapers.com }\end{array}$ \\
\hline $\begin{array}{l}\text { NPIs (alternative } \\
\text { measures) }\end{array}$ & 43 & 1918-1919 & $\begin{array}{l}\text { Cause- and race-specific } \\
\text { mortality data are available for } \\
18 \text { cities in this dataset }\end{array}$ & Markel et al. (2007) \\
\hline $\begin{array}{l}\text { Spring wave } \\
\text { influenza mortality } \\
\text { (alternative } \\
\text { measure) }\end{array}$ & 45 & 1918 & & Crosby (2003) \\
\hline $\begin{array}{l}\text { Infant mortality, } \\
\text { city-specific }\end{array}$ & 43 & 1910 & & Collins (1930) \\
\hline $\begin{array}{l}\text { Air pollution, infant } \\
\text { mortality; city- } \\
\text { specific }\end{array}$ & 878 & 1915-1925 & $\begin{array}{l}\text { Missing data for some } \\
\text { cities/years. Air pollution is } \\
\text { calculated from local coal- } \\
\text { fired electricity generation } \\
\text { capacity }\end{array}$ & Clay et al. (2019) \\
\hline
\end{tabular}

Table 1. Datasets and data sources 

mortality disparities in 1918

\section{A2. No evidence}

Cities with high pre-pandemic infectious disease mortality are also hit hard by the pandemic, but city demographics are unlikely to explain the specific mortality signature of the 1918 pandemic.

B. Did non-pharmaceutical interventions (NPIs) offer protections and disproportionately benefit nonwhites?

B1. NPI implementation associated with race-independent (total) mortality

B2. NPI implementation associated with race-specific mortalities and mortality disparities
NPIs help to explain cumulative total mortality but are unlikely to explain reduced racial disparities.

\section{Social Immunology}

C. Did racial differences in herald wave exposure generate

differences in partial immunity, disproportionately protecting nonwhite communities?

$C 1$. Nonwhites had greater spring wave exposure

C2. Greater spring wave exposure associated with lower fall wave mortality
B1. Yes

\section{B2. No evidence}

Partial immunity is unlikely to explain reduced fall disparities, though herald wave exposure may have mattered for nonimmunological reasons (e.g., behavioral changes). (Note: low statistical power may reduce ability to detect associations;

C2. Mixed evidence calculations are based on potentially (inconsistent) noisy/biased proxy measures) 
D. Did racial differences in early childhood flu exposure to the 1890 influenza virus produce greater influenza mortality among whites compared to nonwhites in 1918 ?

D1. Reduced 1918 disparities are driven by cohorts who would have had 1890 exposure

D2. Proportion of city residents with urban origins is greater for white than nonwhite populations

D3. Proportions of city residents with urban origins positively associated with mortality

D4. Aggregate mortality in the 20-29 and 30-39 age bands is consistent with "reasonable" mortality among the hypothetically imprinted

D5. Estimated imprinting rates are consistent with "reasonable" historical influenza attack rates

\section{D1. Yes}

D.2. Yes

D3. Yes (though

only suggestive)

D4. Yes (but only if

imprinting is close

to ubiquitous in

some cohorts)

D5. Yes (but the

parameter space is

highly constrained

for the 20-29 age

group)
We cannot rule out 1890 exposure as a major driver of high white young adult mortality, and thus reduced disparities, in 1918. If 1890 exposure is to fully account for high white young adult mortality, historical flu exposure and immunological imprinting parameters need to line up in relatively narrow ways, albeit ones consistent with some historical influenza literature. (Note: we are unable to directly measure imprinting.)

Table 2. Possible explanations for reduced racial disparities in 1918 urban pandemic mortality. 


\begin{tabular}{|c|c|c|}
\hline Necessary Conditions for the Imprinting Explanation & Analysis & Result \\
\hline $\begin{array}{l}\text { 1. Reduced aggregate disparities in } 1918 \text { were driven by } \\
\text { cohorts that could have been exposed to the } 1890 \\
\text { virus during critical developmental periods. }\end{array}$ & Empirical & $\begin{array}{l}\text { Yes: Reduced disparities were driven by cohorts aged 20-39 } \\
\text { in } 1918\end{array}$ \\
\hline $\begin{array}{l}\text { 2. Either } \\
\text { a. relevant cohorts of urban white } 1918 \text { populations } \\
\text { had greater exposure to the } 1890 \text { flu than relevant } \\
\text { cohorts of urban nonwhite } 1918 \text { populations or } \\
\text { b. relevant cohorts of these populations had similar } \\
\text { exposures, which swamped other factors that } \\
\text { tended to produce higher non-white influenza } \\
\text { mortality in other years. }\end{array}$ & Empirical & $\begin{array}{l}\text { Suggestive yes (2a): Using urban origins as a proxy for } \\
\text { childhood influenza exposure, young adult urban white } \\
\text { populations had greater exposure than young adult urban } \\
\text { nonwhite populations } \\
\text { Suggestive no (2b): City-level factors were not less } \\
\text { predictive of disparities in } 1918 \text { compared to prior years, } \\
\text { failing to provide evidence of imprinting "swamping" other } \\
\text { factors (analysis reported in the Appendix) }\end{array}$ \\
\hline $\begin{array}{l}\text { 3. Populations with greater } 1890 \text { flu exposure had } \\
\text { higher mortality in } 1918 \text {. }\end{array}$ & Empirical & $\begin{array}{l}\text { Suggestive yes: Using urban origins as a proxy for childhood } \\
\text { influenza exposure, city populations with greater exposure } \\
\text { had higher } 1918 \text { mortality }\end{array}$ \\
\hline $\begin{array}{l}\text { 4. } 1890 \text { influenza exposure was sufficiently } \\
\text { a. prevalent and } \\
\text { b. deleterious to survival in } 1918 \\
\text { to account for reduced racial disparities in the relevant } \\
\text { cohorts. }\end{array}$ & Simulation & $\begin{array}{l}\text { Not disproven: Simulations find that, to account for reduced } \\
\text { disparities, imprinting would need to be highly prevalent } \\
\text { among urban whites in relevant cohorts, but that this } \\
\text { prevalence could result from plausible attack rates. }\end{array}$ \\
\hline
\end{tabular}

Table 3. Summary of evaluation of the "imprinting explanation": the idea that racially differential patterns of early childhood exposure to the 1889-1892

influenza explain the reduced racial disparities in 1918 pandemic mortality. The leftmost column lists necessary conditions for the explanation to hold.

Conditions (1) through (3) are respectively evaluated by tests in Table 2's D1 through D3. Conditions (4a) and (4b) are jointly evaluated through Table 2's Test D4 and the outcome of Test D4 is further evaluated through Table 2's Test D5. 


\section{FIGURES}

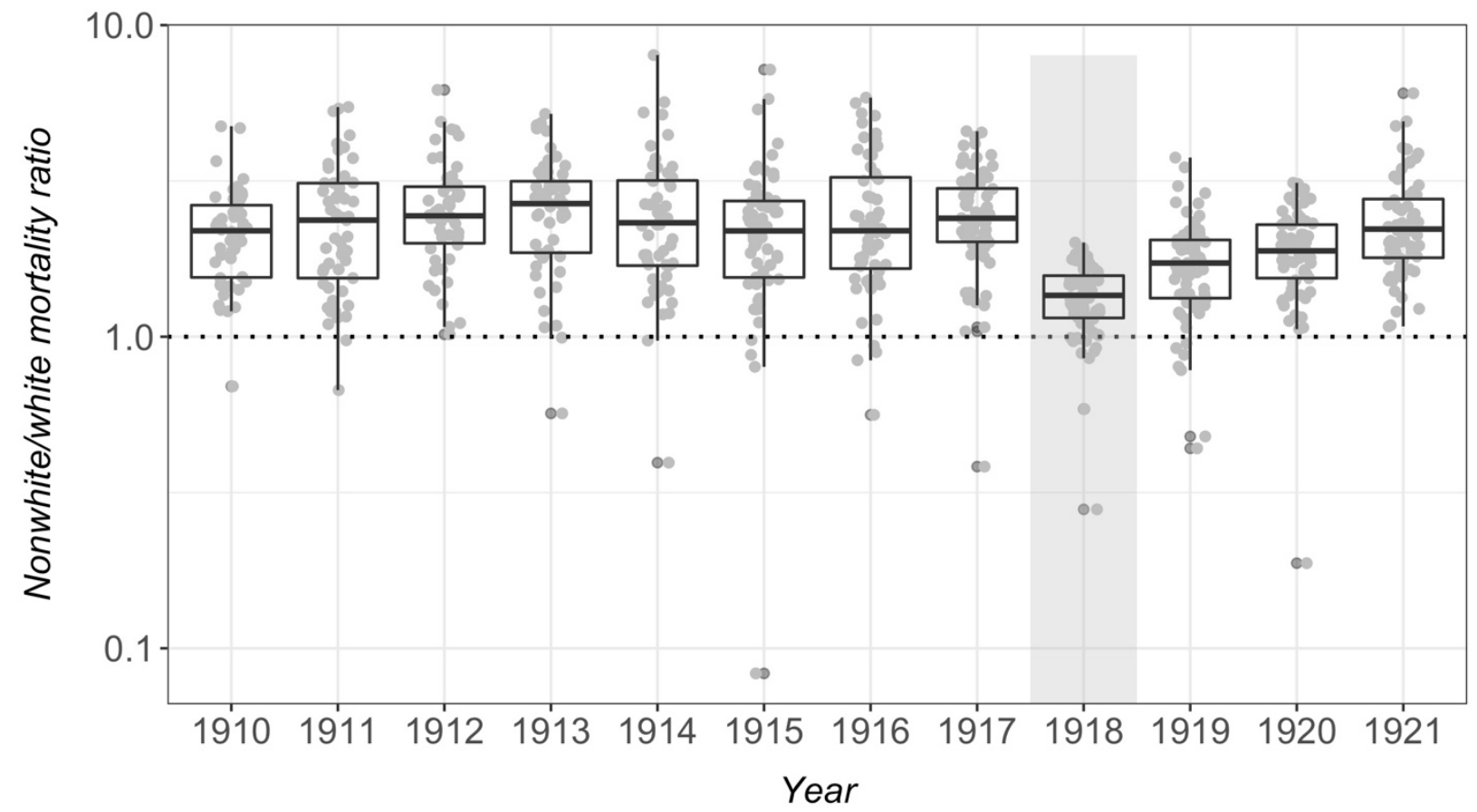

Figure 1. Nonwhite/white ratios of influenza and pneumonia mortality by year. Mortality values (unlogged) are portrayed on a logged-scale y-axis. The 1918 pandemic (shaded in grey) was characterized by uniformly reduced racial disparities in mortality, compared to non-pandemic years. The dotted line marks a mortality ratio of 1 , that is, an equal number of white and nonwhite deaths per 100,000. 

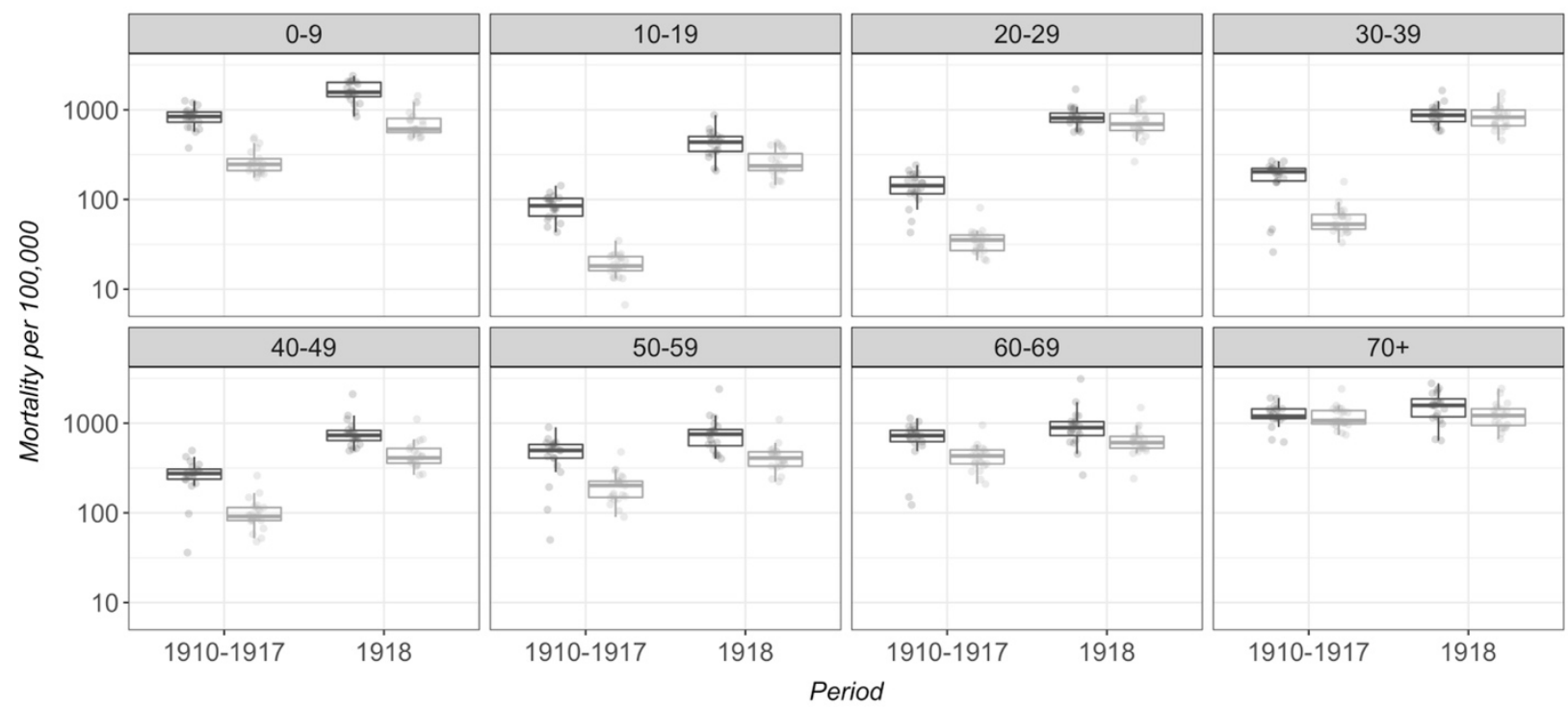

白 nonwhite 官 white

Figure 2. Pre-pandemic (1910-1917) and pandemic (1918) influenza and pneumonia mortality per 100,000 by race and age group. Mortality values (unlogged) are portrayed on a logged-scale y-axis. Mortality among the very young and very old was almost uniformly high. But those aged 20-39 experienced large increases in mortality and the largest declines in nonwhite/white mortality ratios during the 1918 pandemic.
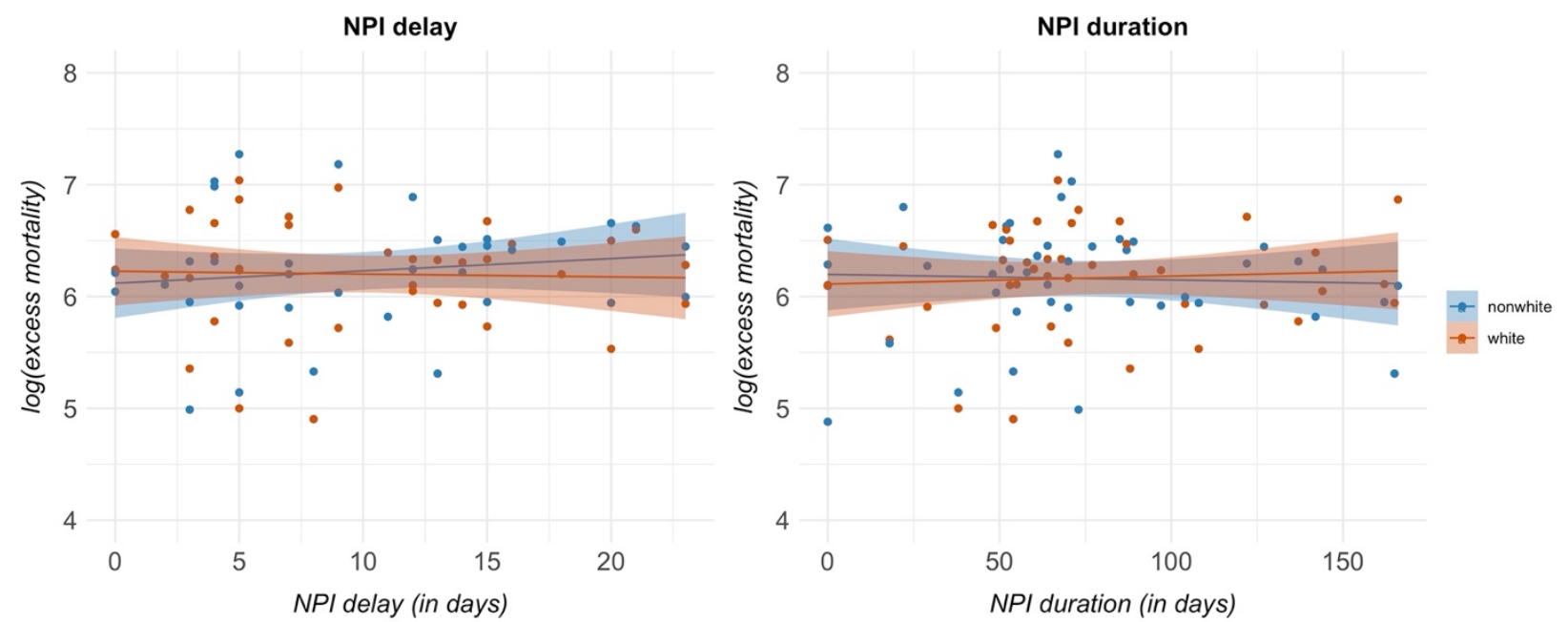

Figure 3. Race-specific influenza and pneumonia excess mortality in 1918, relative to pre-pandemic years, as a function of non-pharmaceutical interventions (NPIs). 

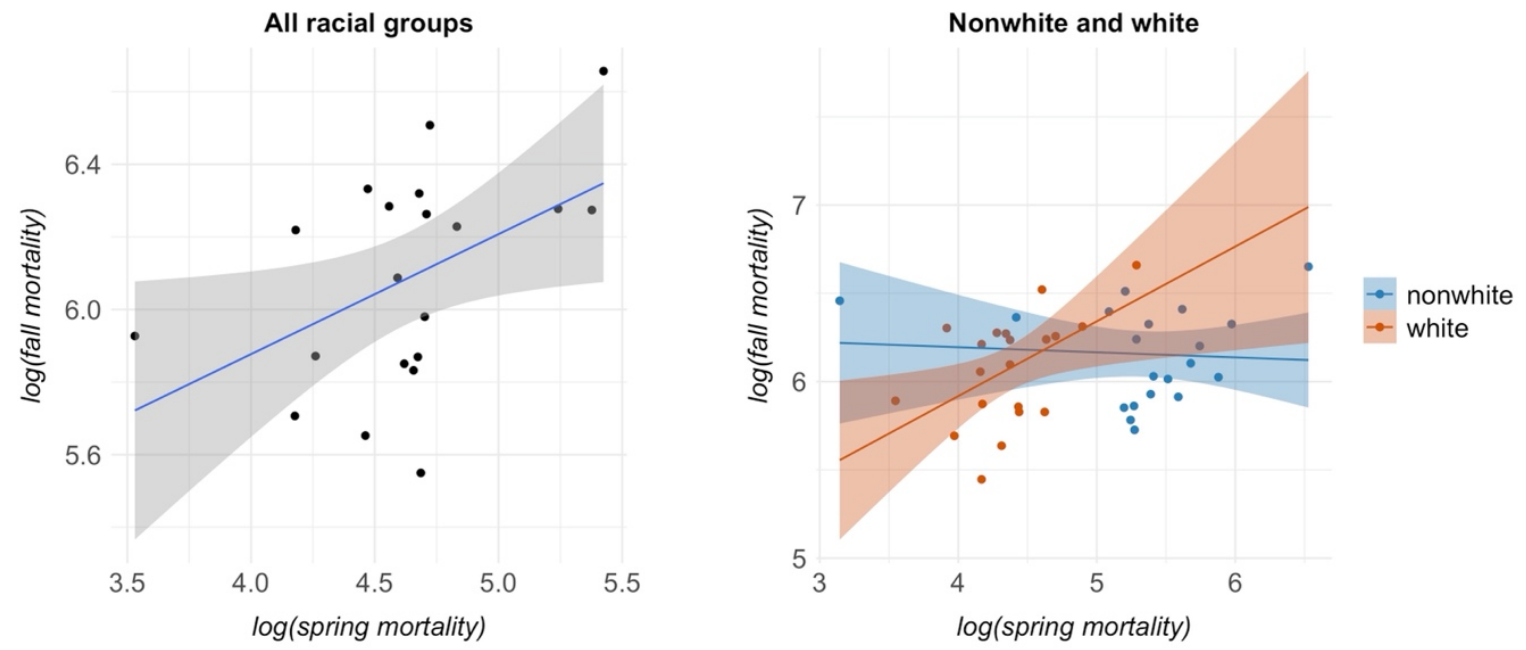

Figure 4. Fall 1918 influenza and pneumonia mortality as a function of spring 1918 influenza and pneumonia mortality, logged, in total and by race.

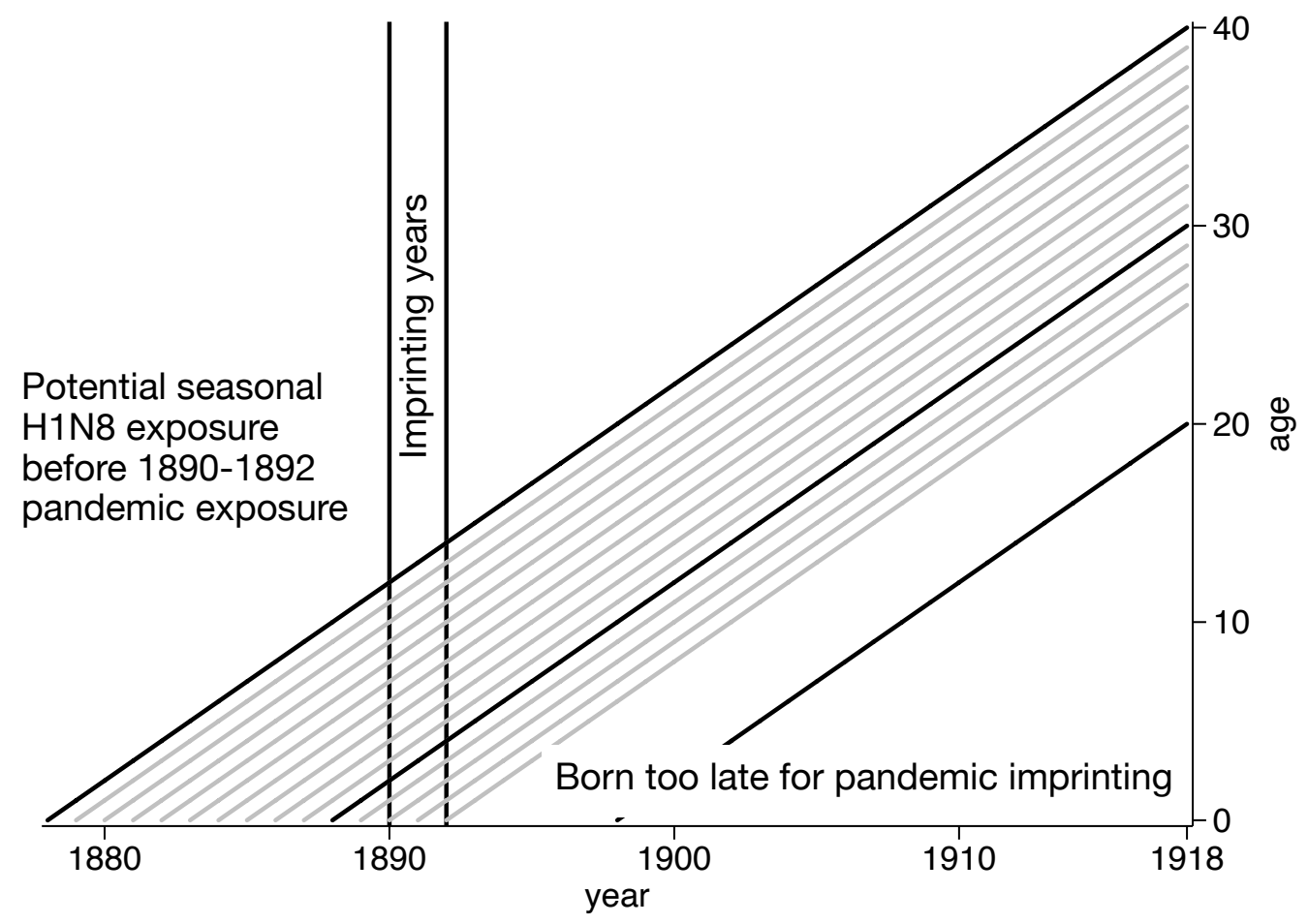

Figure 5. Lexis diagram illustrating cohorts that might have been immunologically imprinted by the 1890-1892 pandemic flu virus, depicted in grey. 


\section{REFERENCES}

Abramitszky, R., Boustan, L., \& Myera, R. (2020). Census Linking Project: Version 1.0 [dataset]. https://censuslinkingproject.org

Abramitzky, R., Boustan, L., Eriksson, K., Feigenbaum, J., \& Pérez, S. (2021). Automated Linking of Historical Data. Journal of Economic Literature, 59(3), 865-918. https://doi.org/10.1257/jel.20201599

Affair Riles Dr. H. L. Clark. (1919, March 20). The Topeka State Journal, p. 7. Topeka, Kansas.

Ager, P., Feigenbaum, J., Hansen, C. W., \& Tan, H. R. (2020). How the Other Half Died: Immigration and Mortality in US Cities (No. w27480) (p. w27480). Cambridge, MA: National Bureau of Economic Research. https://doi.org/10.3386/w27480

Ahmad, F. B., Cisewski, J. A., Miniño, A., \& Anderson, R. N. (2021). Provisional Mortality Data - United States, 2020. MMWR. Morbidity and Mortality Weekly Report, 70(14), 519-522. https://doi.org/10.15585/mmwr.mm7014e1

Bonds, M. H., Keenan, D. C., Rohani, P., \& Sachs, J. D. (2010). Poverty trap formed by the ecology of infectious diseases. Proceedings of the Royal Society B: Biological Sciences, 277(1685), 1185-1192. https://doi.org/10.1098/rspb.2009.1778

Boustan, L., \& Margo, R. A. (2016). Racial Differences in Health in the United States: A LongRun Perspective. In J. Komlos \& I. R. Kelly (Eds.), The Oxford Handbook of Economics and Human Biology (pp. 729-750). Oxford University Press. https://doi.org/10.1093/oxfordhb/9780199389292.013.6

Bristow, N. (1992). American Pandemic: The lost worlds of the 1918 influenza epidemic. Oxford: Oxford University Press. 
Britten, R. H. (1932). The Incidence of Epidemic Influenza, 1918-19: A Further Analysis According to Age, Sex, and Color of the Records of Morbidity and Mortality Obtained in Surveys of 12 Localities. Public Health Reports (1896-1970), 47(6), 303. https://doi.org/10.2307/4580340

Brüssow, H., \& Brüssow, L. (2021). Clinical evidence that the pandemic from 1889 to 1891 commonly called the Russian flu might have been an earlier coronavirus pandemic. Microbial Biotechnology, 14(5), 1860-1870. https://doi.org/10.1111/1751-7915.13889

Byrd, W. M., \& Clayton, L. A. (2001). Race, medicine, and health care in the United States: a historical survey. Journal of the National Medical Association, 93(3 Suppl), 11S-34S.

Centers for Disease Control and Prevention. (n.d.). Data Table. https://wonder.cdc.gov/controller/saved/D76/D189F138. Accessed 21 July 2021

Clay, K., Lewis, J., \& Severnini, E. (2019). What explains cross-city variation in mortality during the 1918 influenza pandemic? Evidence from 438 U.S. cities. Economics \& Human Biology, 35, 42-50. https://doi.org/10.1016/j.ehb.2019.03.010

Collins, S. D., Frost, W. H., Gover, M., \& Sydenstricker, E. (1930). Mortality from Influenza and Pneumonia in 50 Large Cities of the United States, 1910-1929. Public Health Reports (1896-1970), 45(39), 2277. https://doi.org/10.2307/4579795

Crosby, A. W. (2003). America's forgotten pandemic: the influenza of 1918. Cambridge, England: Cambridge University Press.

Dowdle, W. R. (1999). Influenza A virus recycling revisited. Bulletin of the World Health Organization, 77(10), 820-828. 
Dowdle, Walter R. (2006). Influenza pandemic periodicity, virus recycling, and the art of risk assessment. Emerging Infectious Diseases, 12(1), 34-39. https://doi.org/10.3201/eid1201.051013

Ewing, E. T. (2021, April 1). Measuring Mortality In The Pandemics Of 1918-19 And 2020-21. Health Affairs Blog. https://www.healthaffairs.org/do/10.1377/hblog20210329.51293/full/. Accessed 21 December 2021

Feigenbaum, J. J., Hoehn-Velasco, L., \& Wrigley-Field, E. (2020). Did the Urban Mortality Penalty Disappear? Revisiting the Early Twentieth Century's Urban-Rural Mortality Convergence. Minnesota Population Center Working Paper Series. https://doi.org/10.18128/MPC2020-09

Feigenbaum, J. J., Muller, C., \& Wrigley-Field, E. (2019). Regional and Racial Inequality in Infectious Disease Mortality in U.S. Cities, 1900-1948. Demography, 56(4), 1371-1388. https://doi.org/10.1007/s13524-019-00789-z

Frankel, L. K., \& Dublin, L. I. (1919). Influenza Mortality among Wage Earners and their Families: A preliminary statement of results. American Journal of Public Health, 9(10), 731-742. https://doi.org/10.2105/AJPH.9.10.731-a

Frost, W. H. (1920). Statistics of Influenza Morbidity—With Special Reference to Certain Factors in Case Incidence and Case Fatality. Public Health Reports (1896-1970), 35(11), $584-597$.

Gagnon, A., Acosta, J. E., Madrenas, J., \& Miller, M. S. (2015). Is Antigenic Sin Always “Original?” Re-examining the Evidence Regarding Circulation of a Human H1 Influenza 
Virus Immediately Prior to the 1918 Spanish Flu. PLOS Pathogens, 11(3), e1004615. https://doi.org/10.1371/journal.ppat.1004615

Gagnon, A., Miller, M. S., Hallman, S. A., Bourbeau, R., Herring, D. A., Earn, D. JD., \& Madrenas, J. (2013). Age-Specific Mortality During the 1918 Influenza Pandemic: Unravelling the Mystery of High Young Adult Mortality. PLoS ONE, 8(8), e69586. https://doi.org/10.1371/journal.pone.0069586

Gamble, V. N. (2010). “There wasn't a lot of comforts in those days:” African Americans, public health, and the 1918 influenza epidemic. Public Health Reports (Washington, D.C.: 1974), 125 Suppl 3, 114-122.

Gostic, K. M., Ambrose, M., Worobey, M., \& Lloyd-Smith, J. O. (2016). Potent protection against H5N1 and H7N9 influenza via childhood hemagglutinin imprinting. Science, 354(6313), 722-726. https://doi.org/10.1126/science.aag1322

Gostic, K. M., Bridge, R., Brady, S., Viboud, C., Worobey, M., \& Lloyd-Smith, J. O. (2019). Childhood immune imprinting to influenza A shapes birth year-specific risk during seasonal H1N1 and H3N2 epidemics. PLOS Pathogens, 15(12), e1008109. https://doi.org/10.1371/journal.ppat.1008109

Grantz, K. H., Rane, M. S., Salje, H., Glass, G. E., Schachterle, S. E., \& Cummings, D. A. T. (2016). Disparities in influenza mortality and transmission related to sociodemographic factors within Chicago in the pandemic of 1918. Proceedings of the National Academy of Sciences, 113(48), 13839-13844. https://doi.org/10.1073/pnas.1612838113

Grigoryeva, A., \& Ruef, M. (2015). The Historical Demography of Racial Segregation. American Sociological Review, 80(4), 814-842. https://doi.org/10.1177/0003122415589170 
Hallman, S., \& Gagnon, A. (2014). Does Exposure to Influenza Very Early in Life Affect Mortality Risk during a Subsequent Outbreak? The 1890 and 1918 Pandemics in Canada. In M. K. Zuckerman (Ed.), Modern Environments and Human Health (pp. 123-135). Oxford: John Wiley \& Sons, Inc. https://doi.org/10.1002/9781118504338.ch7

Hart, K. D., Kunitz, S. J., Sell, R. R., \& Mukamel, D. B. (1998). Metropolitan governance, residential segregation, and mortality among African Americans. American Journal of Public Health, 88(3), 434-438. https://doi.org/10.2105/AJPH.88.3.434

Hatchett, R. J., Mecher, C. E., \& Lipsitch, M. (2007). Public health interventions and epidemic intensity during the 1918 influenza pandemic. Proceedings of the National Academy of Sciences, 104(18), 7582-7587. https://doi.org/10.1073/pnas.0610941104

Hoffman, B. L. (2011). Influenza activity in Saint Joseph, Missouri 1910-1923: Evidence for an early wave of the 1918 pandemic. PLoS Currents. https://doi.org/10.1371/currents.RRN1287

Hutchins, S. S., Fiscella, K., Levine, R. S., Ompad, D. C., \& McDonald, M. (2009). Protection of Racial/Ethnic Minority Populations During an Influenza Pandemic. American Journal of Public Health, 99(S2), S261-S270. https://doi.org/10.2105/AJPH.2009.161505

Ireland, Merritte W. (1929). The Medical Department of the United States Army in the World War, Vol. IX. Washington, D.C.: Government Printing Office.

Jackman, M. R., \& Shauman, K. A. (2019). The Toll of Inequality: Excess African American Deaths in the United States over the Twentieth Century. Du Bois Review: Social Science Research on Race, 16(2), 291-340. https://doi.org/10.1017/S1742058X20000028

Krishnan, L., Ogunwole, S. M., \& Cooper, L. A. (2020). Historical Insights on Coronavirus Disease 2019 (COVID-19), the 1918 Influenza Pandemic, and Racial Disparities: 
Illuminating a Path Forward. Annals of Internal Medicine, 173(6), 474-481.

https://doi.org/10.7326/M20-2223

Luk, J., Gross, P., \& Thompson, W. W. (2001). Observations on Mortality during the 1918 Influenza Pandemic. Clinical Infectious Diseases, 33(8), 1375-1378. https://doi.org/10.1086/322662

Mamelund, S.-E. (2011). Geography May Explain Adult Mortality from the 1918-20 Influenza Pandemic. Epidemics, 3(1), 46-60. https://doi.org/10.1016/j.epidem.2011.02.001

Mamelund, S.-E. (2018). 1918 pandemic morbidity: The first wave hits the poor, the second wave hits the rich. Influenza and Other Respiratory Viruses, 12(3), 307-313. https://doi.org/10.1111/irv.12541

Markel, H., Lipman, H. B., Navarro, J. A., Sloan, A., Michalsen, J. R., Stern, A. M., \& Cetron, M. S. (2007). Nonpharmaceutical Interventions Implemented by US Cities During the 1918-1919 Influenza Pandemic. JAMA, 298(6), 644. https://doi.org/10.1001/jama.298.6.644

Mathews, J. D., Chesson, J. M., McCaw, J. M., \& McVernon, J. (2009). Understanding influenza transmission, immunity and pandemic threats. Influenza and Other Respiratory Viruses, 3(4), 143-149. https://doi.org/10.1111/j.1750-2659.2009.00089.x

Mulder, J., Nasurel, N., Deggars, E. M., \& Webbers, P. J. (1958). Pre-Epidemic Antibody Against 1957 Strain of Asiatic Influenza in Serum of Older People Living in the Netherlands. The Lancet, 271(7025), 810-814. https://doi.org/10.1016/S0140$6736(58) 91738-0$ 
Navar, A. M., Purinton, S. N., Hou, Q., Taylor, R. J., \& Peterson, E. D. (2021). The impact of race and ethnicity on outcomes in 19,584 adults hospitalized with COVID-19. PLOS ONE, 16(7), e0254809. https://doi.org/10.1371/journal.pone.0254809

Noymer, A. (2010). Epidemics and Time: Influenza and Tuberculosis During and After the 1918-1919 Pandemic. In D. A. Herring \& A. C. Swedlund (Eds.), Plagues and Epidemics: Infected Spaces Past and Present (pp. 137-152). Milton Park, England: Routledge.

Ogedegbe, G., Ravenell, J., Adhikari, S., Butler, M., Cook, T., Francois, F., et al. (2020). Assessment of Racial/Ethnic Disparities in Hospitalization and Mortality in Patients With COVID-19 in New York City. JAMA Network Open, 3(12), e2026881. https://doi.org/10.1001/jamanetworkopen.2020.26881

Økland, H., \& Mamelund, S.-E. (2019). Race and 1918 Influenza Pandemic in the United States: A Review of the Literature. International Journal of Environmental Research and Public Health, 16(14), E2487. https://doi.org/10.3390/ijerph16142487

Olson, D. R., Simonsen, L., Edelson, P. J., \& Morse, S. S. (2005). Epidemiological evidence of an early wave of the 1918 influenza pandemic in New York City. Proceedings of the National Academy of Sciences, 102(31), 11059-11063. https://doi.org/10.1073/pnas.0408290102

Patrono, L. V., Vrancken, B., Budt, M., Düx, A., Lequime, S., Boral, S., et al. (2021). Archival influenza virus genomes from Europe reveal genomic and phenotypic variability during the 1918 pandemic (preprint). Microbiology. https://doi.org/10.1101/2021.05.14.444134

Patterson, K. D., \& Pyle, G. F. (1991). The geography and mortality of the 1918 influenza pandemic. Bulletin of the History of Medicine, 65(1), 4-21. 
Reardon, S. F., \& O'Sullivan, D. (2004). 3. Measures of Spatial Segregation. Sociological Methodology, 34(1), 121-162. https://doi.org/10.1111/j.0081-1750.2004.00150.x

Rentsch, C. T., Kidwai-Khan, F., Tate, J. P., Park, L. S., King, J. T., Skanderson, M., et al. (2020). Patterns of COVID-19 testing and mortality by race and ethnicity among United States veterans: A nationwide cohort study. PLOS Medicine, 17(9), e1003379. https://doi.org/10.1371/journal.pmed.1003379

Roberto, E. (2016). The Divergence Index: A Decomposable Measure of Segregation and Inequality. arXiv:1508.01167 [physics, stat]. http://arxiv.org/abs/1508.01167. Accessed 24 November 2021

Roberts, S. K. Jr. (2009). Infectious Fear: Politics, Disease, and the Health Effects of Segregation. Chapel Hill: University of North Carolina Press.

Ruggles, S., Flood, S., Goeken, R., Grover, J., Meyer, E., Pacas, J., \& Sobek, M. (2020). IPUMS USA: Version 10.0 [dataset]. IPUMS. https://www.ipums.org

Saunders-Hastings, P., \& Krewski, D. (2016). Reviewing the History of Pandemic Influenza: Understanding Patterns of Emergence and Transmission. Pathogens, 5(4), 66. https://doi.org/10.3390/pathogens5040066

Schlabach, E. (2019). The Influenza Epidemic and Jim Crow Public Health Policies and Practices in Chicago, 1917-1921. The Journal of African American History, 104(1), 3158. https://doi.org/10.1086/701105

Shanks, G. D., \& Brundage, J. F. (2012). Pathogenic Responses among Young Adults during the 1918 Influenza Pandemic. Emerging Infectious Diseases, 18(2), 201-207. https://doi.org/10.3201/eid1802.102042 
Shattuck, E. C. (2021). Networks, cultures, and institutions: Toward a social immunology. Brain, Behavior, \& Immunity - Health, 18, 100367. https://doi.org/10.1016/j.bbih.2021.100367

Spreeuwenberg, P., Kroneman, M., \& Paget, J. (2018). Reassessing the Global Mortality Burden of the 1918 Influenza Pandemic. American Journal of Epidemiology, 187(12), 25612567. https://doi.org/10.1093/aje/kwy191

Topeka Free of Flu. (1919, April 10). The Topeka State Journal, p. 6. Topeka, Kansas. Troesken, W. (2004). Water, Race, and Disease. Cambridge, MA: MIT Press.

Valleron, A.-J., Cori, A., Valtat, S., Meurisse, S., Carrat, F., \& Boelle, P.-Y. (2010). Transmissibility and geographic spread of the 1889 influenza pandemic. Proceedings of the National Academy of Sciences, 107(19), 8778-8781. https://doi.org/10.1073/pnas.1000886107

Vaupel, J. W., \& Yashin, A. I. (1985). Heterogeneity's ruses: some surprising effects of selection on population dynamics. The American Statistician, 39(3), 176-185.

Vijgen, L., Keyaerts, E., Lemey, P., Maes, P., Van Reeth, K., Nauwynck, H., et al. (2006). Evolutionary History of the Closely Related Group 2 Coronaviruses: Porcine Hemagglutinating Encephalomyelitis Virus, Bovine Coronavirus, and Human Coronavirus OC43. Journal of Virology, 80(14), 7270-7274. https://doi.org/10.1128/JVI.02675-05

Vijgen, L., Keyaerts, E., Moës, E., Thoelen, I., Wollants, E., Lemey, P., et al. (2005). Complete Genomic Sequence of Human Coronavirus OC43: Molecular Clock Analysis Suggests a Relatively Recent Zoonotic Coronavirus Transmission Event. Journal of Virology, 79(3), 1595-1604. https://doi.org/10.1128/JVI.79.3.1595-1604.2005 
Waitzman, N. J., \& Smith, K. R. (1998). Phantom of the area: poverty-area residence and mortality in the United States. American Journal of Public Health, 88(6), 973-976. https://doi.org/10.2105/AJPH.88.6.973

Weinberger, D. M., Chen, J., Cohen, T., Crawford, F. W., Mostashari, F., Olson, D., et al. (2020). Estimation of Excess Deaths Associated With the COVID-19 Pandemic in the United States, March to May 2020. JAMA Internal Medicine, 180(10), 1336. https://doi.org/10.1001/jamainternmed.2020.3391

Whewell, W. (1858). Novum organum renovatum. In R. E. Butts (Ed.), Theory of Scientific Method. Indianapolis: Hackett.

White, M. J. (1983). The Measurement of Spatial Segregation. American Journal of Sociology, 88(5), 1008-1018.

Woo, G. (2019). Age-dependence of the 1918 pandemic. British Actuarial Journal, 24, e3. https://doi.org/10.1017/S1357321719000023

Worobey, M., Han, G.-Z., \& Rambaut, A. (2014). Genesis and pathogenesis of the 1918 pandemic H1N1 influenza A virus. Proceedings of the National Academy of Sciences, 111(22), 8107-8112. https://doi.org/10.1073/pnas.1324197111

Worobey, Michael, Cox, J., \& Gill, D. (2019). The origins of the great pandemic. Evolution, Medicine, and Public Health, 2019(1), 18-25. https://doi.org/10.1093/emph/eoz001

Wrigley-Field, E. (2020). US racial inequality may be as deadly as COVID-19. Proceedings of the National Academy of Sciences, 117(36), 21854-21856. https://doi.org/10.1073/pnas.2014750117

Zelner, J., Trangucci, R., Naraharisetti, R., Cao, A., Malosh, R., Broen, K., et al. (2021). Racial Disparities in Coronavirus Disease 2019 (COVID-19) Mortality Are Driven by Unequal 
Infection Risks. Clinical Infectious Diseases, 72(5), e88-e95.

https://doi.org/10.1093/cid/ciaa1723 


\section{Appendix to "Racial Disparities in Mortality During the 1918 Influenza Pandemic in United States Cities"}

\section{CONTENTS:}

I. Data and Measures
A. Data collection
B. Estimating influenza deaths
C. Estimating denominators for death rates
D. Excess mortality
E. Additional data

II. Models
A. Segregation
B. Non-pharmaceutical interventions (NPIs)
C. Partial immunity
D. Variable standardization
E. Statistical power

III. Immunological Imprinting Analyses

A. Empirical plausibility checks (Conditions (1)-(3) [see Table 3])

B. Simulated plausibility checks (Condition (4) [see Table 3])

i. $\quad$ First-stage simulations: Lower-bound estimates of cohort imprinting to account for unusual 1918 mortality

ii. Second-stage simulations: Historical flu exposure rates compatible with lower-bound imprinting prevalence

\section{Data and Measures}

\section{IA. Data collection}

Our analyses draw on datasets of race- and cause-specific death counts that were collected by the Department of Commerce, representing cities in the Death Registration Area (Feigenbaum et al. 2019). Our primary data are annual. After limiting this series to cities with at least 20,000 total population in 1918 (based on log-interpolated census counts), at least $3 \%$ nonwhite, and missing data for no more than three years in 1910- 
1917 (since we use pre-pandemic years to construct key measures, as described below), it contains $\mathrm{N}=70$ cities in 1918 (datasets summarized in the article's Table 1).

While the Death Registration Area only included 31 states in 1918, coverage of the urban population included cities both in and out of the DRA. For example, our dataset of race- and cause-specific death counts in 70 U.S. cities includes six cities in Texas in 1918, though Texas did not join the DRA until 1932. This dataset accounts for $53 \%$ of the total nonwhite urban population and $35 \%$ of the total white urban population of the United States in 1918.

We also construct two supplementary datasets that cover a smaller number of cities $(\mathrm{N}=20)$ but allow us to break down race- and cause-specific death counts by age and by month (separately). In comparison to our primary annual mortality data, these supplementary datasets exclude many medium-sized cities that did not report these detailed mortality statistics to the Department of Commerce.

While the "Spanish flu" pandemic continued to cause excess mortality into the spring months of 1919, the vast majority of U.S. deaths occurred prior to January 1919. Compared to pre-pandemic (1910-1917) baseline estimates for each city, median excess mortality spiked to 235 deaths per 100,000 in October 1918 before declining to 61 in November, 71 in December, 33 in January 1919, and 18 in February 1919. To avoid polluting our estimates with post-pandemic mortality, and to standardize our analyses across different mortality datasets, we do not consider 1919 deaths as part of our "pandemic" estimates. However, we note that monthly mortality disparities remained below the pre-pandemic mean until March 1919.

The race-specific measures collected by the Department of Commerce compare white and nonwhite (or, in the original data, "Colored") populations. The latter includes African-Americans, Asian-Americans, and Native Americans. (So-called "Mexicans" were coded as white.) The demographics of the period mean that, outside selected western cities, the non-white population is overwhelmingly African-American.

\section{IB. Estimating influenza deaths}

We estimate deaths due to the 1918 pandemic by combining recorded death counts for influenza and pneumonia. It is well-known that exposure to the 1918 influenza virus also 
enhanced the pathogenesis of bacterial pneumonia (Brundage and Shanks 2008; Morens et al. 2008).

Yet recent studies suggest that this approach may still under-count pandemic deaths because exposure to the influenza virus could also lead to "purulent bronchitis" as a secondary infection (Shanks et al. 2012). Our numerators would then be too low, and our estimates of racial disparities may be biased if incidence rates of bronchitis differed between racial groups or if causes of death were recorded differently-a distinct possibility, given the segregated healthcare system during the early twentieth century. As a sensitivity analysis, we therefore construct a second numerator that also includes a subset of recorded bronchitis deaths. Specifically, we calculate a baseline of expected bronchitis deaths for each city based on the median 1910-1917 death count and add bronchitis deaths in excess of this baseline to our 1918 influenza numerators. Replacing our primary numerator with this alternative estimate of death counts has no significant impact on our findings. Median total mortality during the 1918 pandemic is 690 deaths per 100,000 when including bronchitis deaths, compared to our primary measure of 684. Median nonwhite/white mortality disparity during the pandemic-our main variable of interest-is 1.36 when including bronchitis deaths, and 1.35 when excluding them.

Our estimates of racial disparities may also be biased if nonwhite deaths were more likely to be unreported or if nonwhite causes of death were more likely to be misclassified. As just noted, the most likely source of misclassification-counting influenza-induced deaths as bronchitis deaths-has no material effect on our findings. This remains true if we add bronchitis deaths for nonwhite populations only, on the assumption that nonwhite causes of death may have been recorded with lower accuracy than white causes of death.

We also note that the state's capacity to produce accurate death counts and accurate tabulations of causes of death tended to grow during the period of interest (Kramer 1947, 1950). Municipal and State Boards of Health increased in size and administrative capacity in the early twentieth century (Hoehn-Velasco and Wrigley-Field 2021), local tabulations were replaced with standardized death certificates distributed by the Department of Commerce, and the Bureau of the Census launched efforts to collect standardized vital statistics. Between 1900 and 1918, the number of US states that successfully tabulated at least 90 percent of deaths nearly tripled (Dublin et al. 1928). 
U.S. healthcare remained segregated (McBride 2018), yet these developments make it unlikely that racial differences in the accuracy of reported data was especially high during the late 1910s, and that the observed decrease in mortality disparities was merely an artifact of undercounting nonwhite deaths. To neutralize the observed decrease in racial disparity, approximately 41 percent of nonwhite deaths (and zero percent of white deaths) would have had to have been misclassified or uncounted during the 1918 pandemic; these are extreme misclassification rates that we do not consider plausible.

The unusually small disparities (relative to the extreme inequality of the time) are also robust to measuring pandemic mortality as 1918-1919 rather than 1918 alone, reflecting the pandemic continuing into spring 1919 in some cities. The median 1919 mortality disparity (1.78 in ratio scale) remained below the 1910-1917 median, in large part due to low monthly disparities in January (1.12), February (1.44) and March (1.65). Combined 1918-1919 disparities also remained strikingly low (median nonwhite/white ratio $=1.39$ ), since the average number of monthly influenza deaths during the pandemic's 3-month peak was 8-10 times higher than during the subsequent 12 months.

We note that similarly reduced disparities in 1918 cannot be observed for other prevalent infectious diseases. Tuberculosis mortality decreased steadily between 1910 and 1930 from 150 deaths/100,000 to 50 deaths/100,000 for white populations and from 450 deaths/100,000 to 200 deaths/100,000 for nonwhite populations, without a clearly observable dip in 1918. TB mortality ratios also remained steady. This indicates, first, that reduced disparities in 1918 were a distinct feature of the influenza pandemic rather than a more general anomaly in U.S. infectious disease mortality and, second, that influenza did not simply crowd out TB as a cause of death among universally vulnerable populations. If it had, we would expect to observe a decline in TB mortality during the 1918 pandemic. One attractive feature of our immunological imprinting hypothesis is its compatibility with this unique mortality pattern. It introduces a vulnerability that is influenza-specific (i.e., immune over-reactions to the 1918 viral strain due to early-life exposure to a different influenza strain) and may specifically affect a population (i.e., young adults aged 20-39) that is not commonly at high risk of infectious disease death.

We also note that the decrease in mortality disparities in 1918 and the relative uniformity of low disparities in 1918 (both compared to the pre-pandemic period 19101917) remain observable in mortality estimates that include all causes of death (i.e., all infectious diseases as well as noninfectious diseases and other causes of death). 
However, the size of the observed decrease is smaller. Using all causes of death to estimate race-specific mortalities, we find that the median nonwhite/white disparity was 1.69 during the 1910-1017 period and 1.46 in 1918, both measured in ratio scale. This implies that the nonwhite/white inequality was around 33\% smaller in 1918 than during pre-pandemic years (in our primary dataset, using pneumonia and influenza deaths, the decline is 74\%). Using all causes of death, we find that the standard deviation of nonwhite/white mortality ratios across all cities was 0.39 during 1910-1917 and 0.30 in 1918 (in our primary dataset, the standard deviation decreased from 1.11 to 0.32). These findings are in line with our expectations: Given the sheer number of influenza-induced deaths during the 1918 pandemic, we expect that any patterns from our primary dataset carry over, with reduced magnitude, into mortality estimates that include all causes of death.

\section{IC. Estimating denominators for death rates}

Historical Vital Statistics reports-the original source of our mortality data-report death counts. To convert these into death rates, we estimate race-specific, age-specific populations for each city using the decennial Census via IPUMS-USA (Ruggles et al. 2020). However, the 1920 Census likely reflected substantial population distortions resulting from pandemic mortality and subsequent internal migration, particularly among young adult populations that were predominant in cities. For this reason, we avoid drawing on that Census in constructing our reported population denominators. Instead, our main measure interpolates populations (on log scale) from 1910 to 1930. Our main population measure thus circumvents the problem of 1920 distortions (which an interpolation would carry heavily into 1918 given the proximity of those years in time) but requires us to interpolate populations across a relatively long 20-year period.

We therefore compare our main measures against two alternative mortality estimates. First, we repeat the calculations above but only interpolate populations (on log scale) between 1910 and 1920, based on a reviewer's suggestion that the distortions introduced by the 1920 count may pale against the uncertainties introduced by longer interpolation periods. Using this alternative measure, we observe a reduction in nonwhite/white disparities from 2.40 to 1.45 (compared to a reduction from 2.33 to 1.35 when using 1910-1930 interpolations), and a reduction in the standard deviation of cityspecific disparities from 1.08 to 0.31 (in our main measure, standard deviation reduces 
from 1.11 to 0.32). Compared to the figures presented in the manuscript, this represents a slightly smaller reduction in the magnitude of disparities (68\% vs. $74 \%$ decrease) and a similar reduction in standard deviation across U.S. cities.

Our main mortality estimate also introduces new distortions to the extent that migration patterns changed notably in the 1920s, in racially specific ways, due to both the continuing Great Migration and the immigration quotas of 1921 and 1924. For this reason, we also examine disparities using an alternative measure that avoids drawing on post-1918 Census data altogether by estimating population counts from non-infectious death counts, which were reported annually. Thus, we first interpolate race-specific populations from 1900 to 1910 (when decennial Censuses are available); second, we estimate city population size as a function of non-infectious death counts between 1906 (the first year with race-specific death counts) and 1910 (the last pre-1918 year with reliable population data); and finally, we use those regressions to predict race-specific population size in 1918 using non-infectious death counts. Specifically, we estimate each city "s and racial group $r$ 's population size in year $y, \hat{n}_{i, r, y}$, as a linear function of its noninfectious death counts, I, year $y$, their interaction, and a race-specific fixed effect for city, represented as $c_{i, r}$ :

$$
\hat{n}_{i, r, y}=\beta_{0}+\beta_{1} d_{i, r, y}+\beta_{2} y+\beta_{3} c_{i, r, y} y+\beta_{4, i, r} c_{i, r}+u_{i, r, y}
$$

This regression is fit only on years 1906-1910 (so that estimated population counts draw only from the 1900 and 1910 Censuses, not the problematic 1920 Census or the 1930 Census used in the main denominator). When we use this regression to predict denominators out-of-sample for 1918, we take the average non-infectious deaths from 1915-1917 as the imputed value for 1918, since actual non-infectious deaths in 1918 are likely to be distorted by the pandemic (e.g., because of social distancing and competing risks). Because of gaps in the availability of non-infectious death statistics prior to 1918 , we are only able to calculate this alternative denominator for 48 of the 70 cities from our main dataset. In general, this approach estimates somewhat smaller population sizes than our main population measure. A weakness of this alternative measure is that, since the cause of death coding in U.S. vital statistics changed in 1910, the non-infectious death counts for 1906-1909 are not strictly comparable to those in 1910 and 1915-1917. 
The alternative method's primary virtue is that its assumptions are quite different from those of our main population measure. Its main assumption is that non-infectious death rates changed (declined) at a steady pace from 1906 to 1917.

The descriptive facts and analytical results obtained by using this alternative denominator broadly match those derived from our primary (census-based) mortality estimates, as shown in Figure S1. Median nonwhite/white mortality ratio is $\mathbf{2 . 4 1}$ during pre-pandemic years (1910-1917) and 1.39 during the pandemic-a decrease in racial disparities by $72 \%$, compared to the $74 \%$ decrease derived from our primary estimates. As is the case in our primary analysis, the observed standard deviation of city-specific mortality disparities also declined from 0.98 before the pandemic to 0.49 in 1918 , thus corroborating the finding that racial disparities during the pandemic were uniformly small relative to the period's extreme mortality stratification.

\section{ID. Excess mortality}

Influenza mortality was subject to significant variability across cities and years. Because we want to isolate the impact of the pandemic from other factors that may have influenced mortality rates within each city, several of our analyses require us to compute 1918 excess mortality or control for expected "baseline mortality." We calculate this baseline by extrapolating 1910-1917 trend lines for each city to 1918, and we estimate excess mortality during the pandemic by subtracting this counterfactual baseline from observed 1918 mortality. We selected this approach after also estimating excess mortality from pre-pandemic mortality averages for different time windows (1915-1917; 1912-1916) and from regionally pooled mortality data, both of which produced implausible excess mortality estimates for several cities.

\section{IE. Additional data}

We link mortality rates to socio-demographic variables that varied by city and racial group and were collected from both primary and published sources. These datasets are summarized in the article's Table 1; descriptions of individual variables are also included in the codebook of the replication dataset (<<blinded: link redacted $>>$ ). Our measures of non-pharmaceutical interventions, city-specific segregation indices, and city- and racespecific measures of illiteracy and residential density are based on original data 
collection through newspapers.com and IPUMS-USA. We summarize our methodological approach for these variables in the main article.

Several additional control variables are taken from existing studies. Estimates of city-specific air pollution come from data made available by (Clay et al. 2019), who use the total electricity generated by coal-fired powerplants within 10 miles of a city's center as a proxy for local air pollution. Alternative measures of NPI implementation come from (Markel et al. 2007); and alternative estimates of herald wave mortality are taken from the appendix to (Crosby 2003). These latter two variables replicate our original data; we use them for sensitivity analyses.

Finally, we use linked census-to-census data from the Census Linking Project (Abramitszky et al. 2020; Abramitzky et al. 2021) to construct measures of the geographic origins of the 1918 population. This analysis is described in the section on immunological imprinting, below.

\section{Models}

We make specific predictions about the association between mortality (and mortality ratios) and various socio-demographic or immunological variables in order to test the potential explanations for reduced disparities.

\section{IIA. Segregation, illiteracy, air pollution, and residential density}

Several studies speculate that urban segregation-which varied by city and region during the early twentieth century-may have functioned as an accidental cordon sanitaire that temporarily insulated nonwhite individuals from community transmission of the influenza virus during the 1918 pandemic, thereby depressing nonwhite mortality and mortality disparities (Krishnan et al. 2020; Schlabach 2019). Prior works also suggest that mortality during the pandemic may have been affected by community-specific poverty rates or residential density because the comparatively low access of poor communities to sanitation and handwashing opportunities may have contributed to higher viral reproduction numbers and because the virus may have spread more widely in cramped living quarters where social distancing and the isolation of infected patients proved difficult in practice (Grantz et al. 2016; Økland and Mamelund 2019). One study (Clay et al. 2019) also finds a potential link between city-specific 1918 mortality and coal- 
fired powerplant capacity, which would have resulted in local air pollution and may have increased vulnerability to infectious diseases that affect the respiratory system. Given the high levels of racial inequality in U.S. cities during the early twentieth century, nonwhite/white differences in these variables or racially disparate consequences of ostensibly race-neutral factors like air pollution could plausibly translate into changes in mortality disparities.

We test the association, across cities (denoted $i$ ), between socio-demographic indices $\left(I_{i}\right)$ and 1918 mortality ratios $\left(\varphi_{i}\right)$ with log-linear models (Eq. S2) that control for the baseline mortality ratio of each city ( $b_{i}$, estimated from 1910-1917 trends) and local age composition $\left(a_{i}\right.$, measured as the proportion of city residents aged 20-39). A second set of models adds additional controls for the delay $\left(p_{i}\right)$ and duration $\left(q_{i}\right)$ of nonpharmaceutical interventions (Eq. S3):

$$
\begin{gathered}
\log \left(\varphi_{i}\right)=\beta_{0}+\beta_{1} I_{i}+\beta_{2} b_{i}+\beta_{3} a_{i}+e \\
\log \left(\varphi_{i}\right)=\beta_{0}+\beta_{1} I_{i}+\beta_{2} b_{i}+\beta_{3} a+\beta_{4} p_{i}+\beta_{5} q_{i}+e
\end{gathered}
$$

We fit each model with four different indices of residential segregation, two alternatives proxy measures of air pollution, nonwhite/white ratios in illiteracy rates, and nonwhite/white ratios in residential density (measured either as the percentage of residents living in multifamily homes or as the average number of residents per dwelling) as the main independent variables represented in $I_{i}$ (Table S1).

To test whether coefficients of association in 1918 differed significantly from those in other years, we also run bivariate checks that regress each socio-demographic variable on logged mortality for each year between 1910 and 1930. We extract annual coefficients and compare 1918 values to those of non-pandemic years with a t-test. We find no statistically significant differences between 1918 coefficients and pre-pandemic coefficients. 


\section{IIB. Non-pharmaceutical interventions (NPIs)}

We construct two sets of linear models to test the link between NPIs and 1918 mortality outcomes: the first uses logged mortality (total, nonwhite, and white, see Eq. S4) and the second one uses mortality ratios $\left(\varphi_{i}\right)$ as the dependent variable (Eq. S5). Each model includes variables that capture the delay $\left(\left(p_{i}\right)\right.$ and duration $\left(\left(q_{i}\right)\right.$ of NPIs and controls for the expected baseline mortality (or mortality ratio) of each city $\left(b_{i}\right)$. Additional models add an interaction effect of NPI delay and duration (Eq. S6).

$$
\begin{gathered}
\log \left(M_{i, r}\right)=\beta_{0}+\beta_{1} p_{i}+\beta_{2} q_{i}+\beta_{3} \log \left(b_{i, r}\right)+e \\
\log \left(\varphi_{i}\right)=\beta_{0}+\beta_{1} p_{i}+\beta_{2} q_{i}+\beta_{3} \log \left(b_{i}\right)+e \\
\log \left(\varphi_{i}\right)=\beta_{0}+\beta_{1} p_{i}+\beta_{2} q_{i}+\beta_{3}\left(p_{i} q_{i}\right)+\beta_{4} \log \left(b_{i}\right)+e
\end{gathered}
$$

Results from all models are shown in Table S2. Using the race- and city-specific coefficients obtained from these models, we then employ a Wald test to assess whether the associations in the first set of models differed significantly for nonwhite and white populations. We also re-run our models with NPI measures obtained from (Markel et al. 2007) as our independent variable. In these alternative models we find stronger effects of NPI delay on pandemic mortality, but likewise find no evidence that NPI delay or duration had a direct effect on mortality ratios or race-specific effects that could explain reduced nonwhite/white disparities. Because of the limited overlap between the NPI dataset compiled by Markel et al. and our dataset of infectious disease deaths, these alternative models have a reduced sample size of $n=18$. We thus treat their findings as suggestive corroborating evidence.

\section{IIC. Partial immunity}

The "herald wave" explanation forms part of a broader hypothesis that posits that exposure to influenza HA subtype $\mathrm{H} 1$ prior to the pandemic's main wave during the fall of 1918 may have conferred partial immunity. The different versions of this hypothesis 
are summarized in Table $\mathrm{S}_{3}\left(\mathrm{~V}_{1}-\mathrm{V}_{3}\right)$, along with versions of the hypothesis that 1918 mortality may have been driven in part by harmful exposures prior to 1918 (V4-V6). Versions of the partial immunity hypothesis $\left(\mathrm{V}_{1}-\mathrm{V}_{3}\right)$ are organized in Table $\mathrm{S}_{3}$ in order of how early that prior influenza exposure may have begun. We focus on testing V1 (partial immunity from spring 1918 exposure) since its predictions are the most clearly delineated and because it is the only version of the partial immunity hypothesis that appears in the prior literature on racial disparities in 1918 (Crosby 2003; Økland and Mamelund 2019). We use version V1 as a stand-in for the broader mechanism of protective immunity.

The availability of race- and month-specific mortality data limits us to 20 cities, and slightly fewer depending on the control variables used in each model.

We test the predicted spring/fall association with models that respectively regress logged fall mortality ( $M_{f, i, r}$, for white, non-white, and total mortality; see Eq. S7) and logged fall nonwhite/white mortality ratios ( $\varphi_{f, i}$, see Eq. S8) on logged spring mortality $\left(M_{s, i, r}\right)$ and logged spring nonwhite/white mortality ratios $\left(\varphi_{s, i}\right)$ while controlling for the percentage of residents aged 20-39 $\left(a_{i, r}\right)$ and the delay $\left(p_{i}\right)$ and duration of NPIs $\left(q_{i}\right)$ (Table S4).

$$
\begin{gathered}
\log \left(M_{f, i, r}\right)=\beta_{0}+\beta_{1} \log \left(M_{s, i, r}\right)+\beta_{2} p_{i}+\beta_{3} q_{i}+\beta_{5} a_{i, r}+e \\
\log \left(\varphi_{f, i}\right)=\beta_{0}+\beta_{1} \log \left(\varphi_{s, i}\right)+\beta_{2} p_{i}+\beta_{3} q_{i}+\beta_{5} a_{i, r}+e
\end{gathered}
$$

Our primary models use January-June as the duration of the herald wave and September-December as the duration of the main pandemic. We confirm the robustness of our findings by varying the duration and timing of the spring and fall waves and by substituting NPI measures collected by (Markel et al. 2007) for our original measures.

For convenience, we repeat here the two main weaknesses of these models, both discussed in the main article (in the section on herald wave results). First, to our knowledge, no systematic measurements of herald wave exposure exist. We use racespecific spring mortality as a proxy for race-specific spring exposure, which assumes that infection fatality rates did not differ significantly across racial groups. Unfortunately we 
have no way of systematically assessing this assumption, since the only available data comes from non-random samples of case fatality rates in six U.S. cities and several military camps that were collected during the pandemic's peak (Britten 1932; Frost 1920; Ireland 1929). It suggests that, during that fall wave, Black populations may have experienced a $\sim 30 \%$ higher case fatality rate compared to white populations. If infection fatality was similarly racially disparate during the spring wave, our estimates of nonwhite/white disparities in herald wave exposure may be upwardly biased. This means that we may overestimate the key immunological feature underlying the partial immunity hypothesis (which would especially be a problem if our subsequent analyses had found evidence to support this hypothesis). Moreover, this proxy measure may introduce some additional noise if infection fatality varied meaningfully across cities.

Second, we also note that the statistical power of our models is low. Models constructed from Eq. S7 range from 0.21 (for nonwhite mortality; controlling for NPIs) to 0.62 (for white mortality; controlling for NPIs); the model constructed from Eq. S8 has a power of 0.38. Substituting NPI data from Markel et al. improves statistical power, which ranges from 0.63 to 0.99 in models that control for NPI onset and duration. This means that some of our models are severely underpowered, especially for nonwhite populations. We thus treat results from these models as suggestive rather than conclusive. Power calculations are described in greater detail below.

As a final observation, although we do not systematically explore the causes of high nonwhite spring exposure, we note a statistically significant association between illiteracy and spring wave mortality. This tracks with (Crosby 2003)'s emphasis on community-specific social conditions as a key driver of mortality levels, as well as with the findings by (Grantz et al. 2016) that higher mortality in Chicago was associated with greater illiteracy at the census-tract level.

\section{IID. Variable standardization}

We use raw measures in our primary analyses but also re-run all models discussed above-pertaining to socio-demographic characteristics, NPIs, and herald wave immunity-after standardizing our variables to mean $=0$ and $\mathrm{SD}=1$. We obtain no significantly different results, with one exception: Standardizing Markel et al.'s (2007) NPI measures and using them as the independent variable in one of our supplementary models results in a small but statistically significant positive association between NPI 
duration and fall 1918 mortality ratios, suggesting that cities with longer-lasting NPIs may have experienced mortality disparities closer to those of non-pandemic years (i.e. with a larger number of excess nonwhite deaths). In that scenario, NPIs may have functioned as a normalizing factor that pulled mortality for all racial groups towards their expected baseline. However, we are unable to replicate this finding with nonstandardized variables or with our original NPI data.

\section{IIE. Statistical power}

We conduct a post-hoc power analysis to estimate the achieved power of our regression analyses and improve the interpretation of non-significant results in our models. (Statistical power is commonly defined as $1-\beta$, with $\beta$ as the Type II error rate.) Specifically, we use an F-test for linear multiple regression to test the R2 deviation from zero, using $\alpha=5 \%$ Type I error probability. Using this test, we find that multivariate models that test the association between spring wave exposure and fall mortality are severely underpowered, ranging from 0.21 to 0.62. As indicated above and in the main study, we thus treat our spring/fall results as broadly suggestive, instead of presenting them as definitive refutations of the partial immunity hypothesis. Models testing the associations between mortality ratios, socio-demographic variables, and NPIs have higher statistical power that ranges from 0.81 (association between residential density and mortality ratios, from Eq. S3) to 0.99 (for NPI models derived from Eq. S4).

\section{Immunological Imprinting Analyses}

The immunological imprinting hypotheses that we explore come in two varieties. The canonical version of this broad explanation is an "original antigenic sin" (OAS) account (Francis 1960; Zhang et al. 2019) in that it purportedly occurs specifically among those whose first flu exposure (after losing maternal antibodies around six months of age) was to the 1890 flu (Gagnon et al. 2013; Hallman and Gagnon 2014; Luk et al. 2001; Mamelund 2011; Shanks and Brundage 2012; Worobey et al. 2014). An alternative version of the imprinting hypothesis is that childhood and young adult exposure to the 1890 virus sometimes "refocused" the immune system to produce an OAS-like response even if the 1890 virus was not the individual's first flu exposure (Gagnon et al. 2015). The existence of, and mechanisms underlying, both OAS broadly and refocusing specifically 
are topics of active research and debate in immunology (Gostic et al. 2016, 2019; Monto et al. 2017; Viboud et al. 2020; Viboud and Epstein 2016). The canonical OAS (here dubbed V5) and imprinting-plus-refocusing (V6) hypotheses are summarized and contextualized in Table $\mathrm{S}_{3}$. Table $\mathrm{S} 3$ also notes the hypothesis (V4) that fetal exposure to the 1890-92 pandemic may have produced morbidity that increased vulnerability in 1918. This hypothesis cannot account for elevated mortality among those aged $30+$ in 1918; an alternative, based on morbidity throughout childhood, is theoretically possible but not explicitly considered here.

The hypothesis that reduced aggregate disparities in 1918 are driven by immunological imprinting from the 1890 virus implies several partially-testable necessary conditions which, for convenience, we repeat here from Table 3 in the main article:

1. Low aggregate disparities are driven by cohorts that could have been exposed to the 1890 virus during critical developmental periods.

2. Either

a. relevant cohorts of urban white 1918 populations had greater exposure to the 1890 flu than relevant cohorts of urban nonwhite 1918 populations or

b. relevant cohorts of these populations had similar exposures, which swamped other factors that tended to produce higher non-white influenza mortality in other years.

3. Populations with greater 1890 flu exposure had higher mortality in 1918.

4. 1890 influenza exposure was sufficiently

a. prevalent and

b. deleterious to survival in 1918

to account for disparities in the relevant cohorts.

We evaluate each of these conditions, with roughly diminishing confidence and precision as we proceed from (1) to (4b), using a mixture of empirical and simulation analyses. Because of substantial imprecision in the estimation of our proxy for $1890 \mathrm{flu}$ exposure (urban origins), which is the core measure in our test of conditions (2a) and (3), we do not attempt to assemble the four necessary conditions into a coherent whole 
with consistent parameter ranges, but rather, largely evaluate their plausibility separately.

Since this argument turns on greater imprinting prevalence among urban white vs. urban non-white populations, it implicitly assumes that the individual-level mortality effects of imprinting were not so much larger for non-white populations that they outweighed these hypothesized racial differences in prevalence. The argument is compatible with imprinting having equal effects for each racial group, stronger effects for white individuals (perhaps due to overall more robust immune systems, given better standards of living), or mildly larger effects for non-white individuals, but not with imprinting having vastly larger effects for non-white individuals.

\section{IIIA. Empirical Plausibility Checks (Conditions (1)-(3))}

To evaluate Condition (1) and assess the relative impact of a mortality convergence among white and nonwhite populations in the hard-hit age cohorts 20-29 and 30-39 on the overall decline in mortality disparities, we construct a counterfactual model that allows us to simulate 1918 disparities without such a mortality convergence among those aged 20-39. Because this counterfactual model requires the use of age- and race-specific mortality data from 1910 to 1918, it is based on death counts from 20 cities only. For this dataset, the median nonwhite/white mortality ratio was 2.51 during the pre-pandemic years 1910-1917, and 1.49 during the 1918 pandemic-a 41\% change in ratio values. We simulate a counterfactual scenario by assuming that those aged 20-29 and 30-39 had the same nonwhite/white mortality ratios during the pandemic as they had during the prepandemic period 1910-1917. For each city in the dataset, we take the observed 1918 nonwhite mortality but adjust the 1918 white mortality until the resulting ratio matches the city's pre-pandemic median ratio. This calculation equalizes nonwhite and white excess mortality (in proportional scale) during the 1918 pandemic for age cohorts 20-29 and 30-39. In this counterfactual scenario, the median nonwhite/white mortality ratio, aggregated across all ages, declines from its pre-pandemic value of 2.51 to $2.27-\mathrm{a} 10 \%$ change in ratio values. This suggests that the stark mortality convergence among those aged 20-39 was responsible for around three fourths of the total decline in mortality disparities during the 1918 pandemic (10\% counterfactual / 41\% actual decline). 
To evaluate Conditions (2) and (3), we use urban origins as a proxy for greater 1890 flu exposure. Since we lack a direct measure of urban origins, we use the IPUMS Complete Count Census (Ruggles et al. 2020) and link individuals backwards from 1910 to 1900 with the crosswalk produced by the Census Linking Project (Abramitszky et al. 2020; Abramitzky et al. 2021). This enables us to connect individuals who lived in cities in 1910 to their location in 1900 , with location in 1900 proxying location in 1890 . (The original, individual-level manuscripts for the 1890 Census were destroyed in a fire in 1921; see Dorman 2008.) We expect that migrations reflected both cohort-specific and age-specific patterns, so we examine the cohorts aged 10-39 in 1910, even though those older than 31 in 1910 would have been in their 40 s by 1918 . We examine all cities with linkable populations (city $\mathrm{N}=601$ ). Among those urban residents who could be linked and who were born in the United States, across 10-year cohort blocks, $40-54 \%$ of nonwhite and $65-74 \%$ of white people lived in cities in 1900 . Showing a similar racial divergence, $14-17 \%$ of nonwhite and $28-33 \%$ of white people had been in cities of at least 100,000 people in 1900 . However, the proportion of these cohorts linkable to 1900 is small-only $14-28 \%$ of the various race-specific cohort groups. We estimate the portion of white and nonwhite cohorts who were in cities in 1890 by assuming that the urban status of the portion of the US-born population that could be linked to 1900 proxies the urban status of all US-born (even those who could not be linked) in 1890, and that half of the urban foreign-born were in cities in 1890 . For context regarding this arbitrary assumption about the foreign-born, we note that, among the 1910 white urban population, the proportion foreign-born ranged from one-quarter (for the cohorts aged 20-39 in 1918) to one-third (for those aged 20-39 in 1910); in contrast, the equivalent proportions for the 1910 urban non-white population are $8 \%$ and $11 \%$, respectively. Given the uncertainty surrounding this estimation, we use the resulting rough estimates only to assess the general plausibility of the idea that white young adults were more likely than nonwhite young adults to have had urban origins (Condition (2)). We conclude that this is plausible.

In evaluating Condition (2), we also note that differential exposure to the 1890 flu is not the only plausible version of the imprinting explanation. It may be that vulnerabilities due to immunological imprinting simply took over as a key driver of mortality during the 1918 pandemic, effectively crowding out factors that explain high nonwhite/white disparities during non-pandemic years and thereby reducing mortality disparities during the pandemic. Our simulations (described in detail below) are agnostic 
to this possibility. Empirically, however, we find no evidence that imprinting replaced poverty or residential density as a driver of infectious disease mortality. If this was the case, we would expect socio-demographic indicators to have become substantially less predictive of 1918 mortality than they had been in prior years. We would also expect that higher influenza mortality led to an observable dip in mortality from other infectious diseases like tuberculosis. Neither was the case: the predictive power of sociodemographic indicators and race-specific tuberculosis mortality rates did not differ much between the 1910-1917 period and the 1918 pandemic.

Building on the assessment of Condition (2), to evaluate Condition (3), we explore whether city-level variation in the proportion of linkable white and nonwhite young adults in 1918 who were in urban areas in 1900 is associated with flu mortality in 1918. To do this, we construct a series of models that focus specifically on residents aged 20-39 in 1918-the age cohorts that were most affected by the 1918 pandemic and potentially exposed during childhood to the $1890 \mathrm{flu}$. These models regress race-specific logged mortality and logged mortality ratios on the percentage of residents who were urban residents in 1900, controlling for city-specific NPIs and for each city's baseline mortality, calculated from 1910-1917 mortality trends. We find that cities with a higher proportion of 1918 residents who were in urban areas in 1900 experienced lower pandemic mortality ratios (Table $\mathrm{S}_{5}$ ) - a plausible finding, since low mortality ratios were primarily due to unexpectedly high mortality among whites aged 20-39 (who would been disproportionately likely to have been urban residents in 1900, and thus been more likely than nonwhite urban residents to have been exposed to the $1980 \mathrm{flu}$ ). Adding controls for city-specific NPIs pushes this association outside the range of statistical significance, reduces our sample size to 14 cities, and limits the statistical power of our models due to the limited overlap in cities for which linked census data as well as NPI data are available.

In sum, our empirical analyses fail to refute the immunological imprinting hypothesis. In the suggestive ways that we are able to evaluate, they are consistent with the necessary conditions (1-3) that the hypothesis requires.

\section{IIIB. Simulated Plausibility Checks (Condition (4))}

The overall goal of our simulations is to develop some metrics that can evaluate the plausibility of the hypothesis that imprinting by the 1890 virus explains the extremely 
high mortality of urban whites, in particular, in their 20 s and 30 s in 1918. Here, we first summarize the logic of our full set of simulations before delving into their details.

The simulations come in two stages that jointly comprise an attempted reductio ad absurdum of the assumption that immunological imprinting with the 1890 virus accounts for high white mortality in 1918. In the first stage of our simulations, we conceptualize the age groups 20-29 and 30-39 as a group of single-year cohorts ${ }^{1}$ that are a mixture of individuals who were and were not imprinted by the 1890 virus. In this stage, our goal is to, first, estimate jointly-possible distributions of the proportion of each cohort that is imprinted and the mortality of the imprinted for each racial group. We do this using observed mortality for age groups (e.g., ages 20-29) and the assumption that, for non-imprinted people, mortality among those aged 20-39 would not be unusually high relative to other age groups. Second, we place an upper bound assumption on the hypothetical mortality of the imprinted in order to derive lower-bound assumptions on the proportion of the cohort that is imprinted. This estimated lower-bound estimate of the proportion of each race-specific cohort that is imprinted by the 1890 virus is the output of the first stage of simulations, and can be evaluated for plausibility against estimates from Worobey et al. (2014). The second stage of simulations, described below, suggestively tests the plausibility of these lower-bound assumptions about the prevalence of imprinting, specifically among whites. Ultimately, this gives us a way to evaluate the plausibility of the starting assumption (that powered the first stage of simulations) that imprinting fully accounts for the high mortality of the 20-29 and 30-39 age groups of urban whites in particular.

IIIBi. First-stage simulations: Lower-bound estimates of cohort imprinting to account for unusual 1918 mortality

We express the observed 1918 influenza and pneumonia mortality of cohort/age groups $I$ (i.e., aged $i=20-29$ or aged $i=30-39$ in 1918) and racial group $r, \overline{\mathrm{M}}_{r}(I)$, as the

${ }^{1}$ When period is fixed at 1918, the same categorizations can be conceptualized as age or cohort groupings. This first stage of simulations is a bridge between our empirical analyses, in which these groupings are thought of as age groups, to the subsequent analysis that simulates their influenza exposures over time, in which they are conceptualized as cohorts. Strictly speaking, this first-stage analysis operates on ages; the people who die at age 28 in 1918 could have been born in 1890 or in 1889 (and died before their birthday in 1918). However, since the overwhelming bulk of deaths in 1918 occurred late in the year, between September and December, when we link these simulations to the subsequent set of simulations, we treat age and cohort as synonymous by assuming that people die at the age they would have been at the end of 1918 . 
unweighted average over single-year cohort/ages $i \in I$ (e.g., aged $i=28$ in 1918), of the cohort-specific average mortality of imprinted $\left(\mu_{r, m}(i)\right)$ and non-imprinted $\left(\mu_{r, \sim m}(i)\right)$ cohort members, weighted by the proportion of the cohort that is imprinted by the 1890 $\operatorname{virus}\left(\pi_{r}(i)\right)$ :

$$
\overline{\mathrm{M}}_{r}(I)=\frac{\left[\sum_{i} \pi_{r}(i) \mu_{r, m}(i)+\left(1-\pi_{r}(i)\right) \mu_{r, \sim m}(i)\right]}{10},
$$

which can be translated into functions of age groups rather than single ages, as:

$$
\overline{\mathrm{M}}_{r}(I)=\Pi_{r}(I) M_{r, m}(I)+\left(1-\Pi_{r}(I)\right) M_{r, \sim m}(I)
$$

in terms of the cohort-aggregate proportion exposed, $\Pi_{r}(I)=\sum_{i} \frac{\pi_{r}(i)}{10}$. We use lowercase letters to denote single-age quantities, capital letters to denote quantities for 10-year cohort/age groups, and the overbar notation to denote quantities aggregated over imprinting status. The single-year cohorts $i$ are unweighted (in Eq. S9a) due to uncertainty about true cohort sizes given pandemic distortions in the 1920 Census and age heaping in the 1910 Census; thus, we assume that, within each larger grouping, each annual cohort/age group is the same size.

The cohort group-specific, race-specific mortality, $\overline{\mathrm{M}}_{r}(I)$, is observed (Figure 2). Cohort-specific, race-specific mortality among the non-imprinted, $\mu_{r, \sim m}(i)$, is estimated by performing a linear interpolation of logged age group-specific mortality in 1918, for age groups 10-19 and 40-49, on single years of age. The observed mortality of these age groups is attributed to single ages 25 and 45, respectively; other single-age mortality estimates are interpolated. ${ }^{2}$

${ }^{2}$ Gagnon et al. (2015) argues that immunological refocusing may occur at ages as old as 30, though with declining prevalence over age. This implies that some people as old as 58 in the fall of 1918 may have been immunologically imprinted with the 1890 virus, raising the concern that our measure of "non-imprinted" mortality may be polluted with partially-imprinted cohorts. This pollution would bias our estimates of nonimprinted mortality upward and imprinted mortality downward. However, alternative specifications that impute mortality in the 20 and 30 from ages 10-19 and 50-59 age groups, and from the 10-19 and 60-69 age groups, produce very similar estimates of the simulation outcome, namely, of the proportion of the 
The single-age prevalence of imprinting, $\pi_{r}(i)$, is simulated over a wide range of values. Cohorts aged 30-39 in 1918 are simulated at imprinting prevalence $0, .1, .25, .5$, .75 , and .9, with the constraint that no older cohort (born farther from 1890) have greater imprinting prevalence than any younger cohort, yielding 31,680 prevalence combinations. Cohorts aged 28 or 29 in 1918 are simulated at imprinting prevalence ranging from .3 to 1 in units of .05, while cohorts aged 25, 26, or 27 are simulated at imprinting prevalence ranging from o to 1 in units of .05. The relationship between prevalence for cohorts aged 28 and 29 is unconstrained; for other cohorts in the 20 , no younger cohort (born farther from 1890) can have greater imprinting prevalence than any older prevalence. For cohorts aged 20-24, the proportion of the cohort imprinted by the 1890 virus is assumed to be zero (Figure 5 ) ${ }^{3}$ These rules yield 72,247 prevalence combinations for the 20-29 age group. ${ }^{4}$

Using these simulated prevalence values, mortality among the non-imprinted, aggregated over age groups, $M_{r, \sim m}(I)$, is estimated as:

$$
M_{r, \sim m}(I)=\frac{\sum_{i}\left(1-\pi_{r}(i)\right) \mu_{r, \sim m}(i)}{\sum_{i}\left(1-\pi_{r}(i)\right)}
$$

and likewise, mortality among the imprinted, aggregated over age groups, can be estimated as:

cohort that must be imprinted (the outcome that feeds into the second set of simulations). Across age and racial groups, these alternative specifications estimate minimum prevalence in the "constrained" models (Fig $\mathrm{S}_{3}$, Panel B, below) with a difference from the main model of 0-2 percentage points.

3 The 1890 virus continued to produce outbreaks as late as 1895 , but its pandemic form is typically described as lasting 1889-1892. If imprinting ceased in 1892, the cohort aged 25 at the beginning of 1918 would also have had imprinting rates of o. In this first stage of simulations, we allow those who turn 25 in 1918 to be imprinted, thus assuming the pandemic continued into 1893. In the second stage (below), where we follow cohorts, we make an alternative set of assumptions about the pandemic's timing, described in Appendix footnote 11 .

4 The simulations for the 30-39 age group are simulated at a coarser resolution than the 20-29 age group because the simulation procedure checks whether the constraints (e.g., that one cohort not have higher exposure than another) are satisfied on every possible combination of values. Thus, the assumption that no one younger than 25 is imprinted means that the finer-grained 20 s parameters need to be checked at only $2,083,725$ value combinations, while the coarser 30 parameters are checked at $60,466,176$ combinations. This makes a finer-grained parameter set for the 30 ages computationally infeasible. 


$$
M_{r, m}(I)=\frac{\sum_{i} \pi_{r}(i) \mu_{r, m}(i)}{\sum_{i} \pi_{r}(i)}
$$

However, in contrast to the interpolated values of $\mu_{r, \sim m}(i)$, derived from the assumption that imprinting fully accounts for the 20s/30s age bump, we have no direct estimates of the single-age mortality of the exposed, $\mu_{r, m}(i)$. For simplicity, we assume that the racespecific mortality of the imprinted does not vary across single ages within age groups, $\mu_{r, m}(i)=\mu_{r, m}(I)$.

Using Eqs. S9b, S10, and S11, and plugging in observed values of aggregate mortality $\overline{\mathrm{M}}_{r}(I)$ and the estimated single-age mortality of the non-imprinted, $\mu_{r, \sim m}(i)$, lets us jointly estimate the exposed proportion of each cohort, $\pi_{r}(i)$, and the mortality of the imprinted, $\mu_{r, m}(I)$. The resulting possibility space is shown in Figure S2, Panel A. The lower the mortality of the exposed (y-axis), the more individuals must be exposed (xaxis) in order to generate the high observed aggregate mortality rates; conversely, the fewer individuals are imprinted, the higher the imprinted group's mortality must be.

As a final step, we impose an arbitrary but reasonable constraint on the magnitude of imprinted mortality: the 1918 mortality of the imprinted individuals in their 20 s or 30 should not exceed the same-race 1918 mortality of people aged 70+, $\mu_{r, m}(I) \leq M_{r}(70+)$ (Figure S2, Panel B). The results imply very high mortality among imprinted individuals unless imprinting was close to ubiquitous in the urban white 2529 cohorts. For the mortality of the imprinted individuals in their 20 s to be lower than 1918 mortality of same-race individuals who are aged $70+$, at least $28.5 \%$ of the nonwhite and $42.5 \%$ of the white individuals in this age group would need to be imprinted. Since only half of the 20-29-year-old cohorts were old enough to be imprinted, this implies that the proportion of 25-29-year-olds who were imprinted would need to be double those values, generating the $85 \%$ (for whites) figure discussed in the article and portrayed visually in Fig. S2. Fig. S2 also shows that these hypothetical high levels of imprinting among white cohorts produce mortality estimates compatible with the constraint that imprinted nonwhite individuals would have had higher mortality than imprinted white individuals; we do not impose this assumption, but use it as a check on the plausibility of the estimates. Finally, for partial calibration of these estimates, as 
noted in the article, serological evidence from the Netherlands (not from a specifically urban population) found that about half of the 1893 birth cohort showed evidence of early H3 imprinting (Dowdle 1999).

The proportion who would need to be imprinted is higher for the white than the nonwhite population because white mortality had a larger increase among those aged 20-39, compared to the surrounding ages, than nonwhite mortality did. The proportion of imprinting-eligible cohorts that would need to be imprinted is similarly smaller in the 30-39 age range, for white and nonwhite cohorts, because twice as many cohorts in that age range are imprinting-eligible. Thus, the constraint that imprinted individuals in their 30 s have lower mortality than same-race individuals aged $70+$ is compatible with white exposure levels of $38 \%$ and nonwhite exposure levels of $30 \%$ across the $30-39$ age group. ${ }^{5}$

The simulations estimate hypothetical imprinting rates conditional on surviving to young adult ages. Since children who were exposed to the pandemic 1890-1892 virus presumably were less likely to have survived to young adult ages than children who were not exposed, and since presumably not everyone who was exposed to the 1890 virus even as a first flu became imprinted, these hypothetical proportions imprinted may imply close to universal childhood exposure, for these cohorts of whites, to the 1890 virus. On the other hand, these simulations are predicated on immunological imprinting fully accounting for the unusually high mortality among those aged 20-39 (compared to surrounding age groups, which also experienced far higher than typical mortality in 1918); less extreme estimates would be compatible with immunological imprinting mechanisms explaining only part of the elevated young adult mortality.

IIBii. Second-stage simulations: Historical flu exposure rates compatible with lowerbound imprinting prevalence

Drawing on the estimated lower-bound imprinting prevalence from the first stage of simulations, our second stage explores what ranges of rates of historical exposures and immunological responses are compatible with these lower-bound estimates for whites.

\footnotetext{
${ }^{5}$ As seen in Fig. S2, the 30 ages also evince greater variation in the hypothetical mortality of imprinted individuals associated with each level of imprinting prevalence. This occurs because imprinting prevalence levels can be reached with a greater diversity of combinations of cohorts, whose non-imprinted members have different imputed mortality.
} 
We focus on whites because they are the more constrained population (i.e., their lower bound imprinting estimate is higher). Specifically, we explore what parameter combinations can generate imprinting prevalence of $80 \%$ (slightly smaller than the hypothetical imprinting prevalence derived from the first set of simulations for the white 25-29 age groups) and 35\% (slightly smaller than the hypothetical imprinting prevalence for the white 30-39 age groups). This analysis treats the lower-bound imprinting prevalence estimated for the aggregate of several cohorts (in the first stage) as an estimate of single-cohort imprinting prevalence. This second set of simulations should be understood as a lens to assess, very roughly, whether the results from the first set of simulations imply that the 1918 mortality increase in key cohorts, among urban whites, was too large to have plausibly been driven by immunological imprinting.

This second set of simulations revolves around three parameters: an annual rate of H1N8 influenza ${ }^{6}$ exposure experienced before $1890, \lambda_{H 1 N 8}$; an annual rate of exposure to the $1890 \mathrm{flu}, \lambda_{1890}$, experienced between 1890 and 1892; and an annual rate of "refocusing," $\lambda_{\text {ref }}$. We explore a parameter space bounded by annual H1N8 exposure $\left(\lambda_{H 1 N 8}\right)$ ranging from $1 \%$ to $70 \%^{7}$ in steps of 1 percentage point prior to 1890 ; annual 1890 virus exposure $\left(\lambda_{1890}\right)$ ranging from $1 \%$ to $70 \%{ }^{8}$ in steps of 1 percentage point from 1890-1892 ${ }^{9}$; and refocusing rates, conditional on having been exposed to prior H1N8 followed by the 1890 virus ( $\lambda_{\text {ref }}$ ), at $0 \%$ to $80 \%$ ranging in steps of 5 percentage points. Within this parameter space, we simulate cohorts born between 1877 and 1892 and

\footnotetext{
${ }^{6}$ More generally, our model assumes that some influenza HA Group 1 subtype circulated before 1889 . Worobey et al. (2014) hypothesizes that H1N8 was in circulation from 1847-1889.

7 For comparison, Chunara et al. (2015) estimates seasonal influenza attack rates for modern U.S. populations aged 20-64, with mixed vaccination status, ranging from 7.1-37.9\% (ranging over two flu seasons and male, female, or aggregate rates). Molinari et al. (2007) estimates modern seasonal flu attack rates at $20 \%$ for ages $0-4,10 \%$ for ages $5-17$, and $7 \%$ for adult ages up to 65 .

8 For comparison, Valleron et al. (2010) estimates attack rates of the 1889 flu, across a large set of international cities, as having a median $60 \%$ and inter-quartile range of $45-70 \%$; for the three U.S. cities studied, the mean is $40 \%$. These reflect attack rates for $1889-90$, the height of the pandemic.

9 In this second stage of simulations, we assume that the pandemic largely ended in 1892. Our second stage also assumes that seasonal flu (e.g., H1N8) transmission continued into 1889 and pandemic flu (the "1890 virus") emerged in force only in 1890 , even though the flu arrived in U.S. port cities at the end of 1889 . These assumptions also produce more conservative estimates (i.e., more likely to disconfirm the immunological imprinting hypothesis by producing unrealistically high estimates of the pandemic flu attack rate necessary to reach high imprinting prevalence). However, our simulations also assume constant pandemic transmission over 1890-1892, even though transmission likely peaked in 1890. This simplifying assumption limits the conservativeness built into the choice of simulated pandemic years.
} 
"follow" them until the end of 1892. We assume that exposures to the non-pandemic version of the 1890 virus after antigenic drift do not have the same imprinting consequences; the imprinting rate is zero after 1892. For model simplicity, these exposure, transmission, and refocusing rates are assumed to be constant over age and over year (both of which are unrealistic assumptions).

We also make several additional assumptions. Most importantly, we assume that everyone who is exposed to the 1890 flu is imprinted with it (although our model form is compatible with alternative assumptions that would change the interpretation of the $\lambda_{1890}$ parameter, which we discuss below). Additionally, we assume that all rates are constant over the years in which they operate; that individuals were born, on average, halfway through their birth year; and that exposures (to H1N8 or the 1890 flu) are only relevant after age 6 months (approximating when babies lose maternal antibodies). We also assume that individuals' deaths in 1918 occurred after their birthdays (so that, for example, those who died at age 29 were born in 1889, not 1888), which is reasonable given that 1918 pandemic mortality was concentrated at the end of the year. And finally, we ignore selective mortality, which means that the rates reflect rates conditional on surviving to be young adults in 1918. If (as is highly plausible) those exposed to either flu were more likely to die before 1918 than those who were not exposed, our exposure parameters thus actually imply larger flu exposure rates among the full childhood cohorts. ${ }^{10}$

The cumulative probability of not having been exposed to H1N8 by 1890 is given, for a cohort with birth year $c$, by:

$$
P_{c}(\sim H 1 N 8)=\left\{\begin{array}{c}
1 \text { if } c \geq 1890 \\
1-.125 \cdot \lambda_{H 1 N 8} \text { if } c=1889 \\
\left(1-.125 \cdot \lambda_{H 1 N 8}\right)\left(1-.625 \cdot \lambda_{H 1 N 8}\right)\left(1-\lambda_{H 1 N 8}\right)^{(1888-c)} \text { if } c<1888
\end{array}\right.
$$

These cumulative probabilities reflect that each individual experiences exposure rate $\lambda_{H 1 N 8}$ in each year in which they are at least six months old during the full year.

\footnotetext{
${ }^{10}$ Alternatively, our exposure rates can be reinterpreted as rates reflecting the joint probability of exposure and survival, which-in the presence of selective mortality-produces the same practical upshot that true exposure rates would be higher than our "exposure" parameters.
} 
However, in each the first two calendar years in which an individual is alive, they will on average spend less than a full year being at least six months old: 0.125 years in their birth year and 0.625 years in their second year. ${ }^{11}$

The cumulative probability of not having been exposed to the pandemic form of the 1890 virus at ages older than six months is given by:

$$
P_{c}(\sim 1890)=\left\{\begin{array}{c}
1 \text { if } c \geq 1893 \\
1-.125 \cdot \lambda_{1890} \text { if } c=1892 \\
\left(1-.125 \cdot \lambda_{1890}\right)\left(1-.625 \cdot \lambda_{1890}\right) \text { if } c=1891 \\
\left(1-.125 \cdot \lambda_{1890}\right)\left(1-.625 \cdot \lambda_{1890}\right)\left(1-\lambda_{1890}\right) \text { if } c=1890 \\
\left(1-.625 \cdot \lambda_{1890}\right)\left(1-\lambda_{1890}\right)^{2} \text { if } c=1889 \\
\left(1-\lambda_{1890}\right)^{3} \text { if } c \leq 1888
\end{array}\right.
$$

These exposure rates reflect the same logic about the exposure time at ages older than 6 months during the first two calendar years of life as in Eq. S12.

The probability of being imprinted is the joint probability of being exposed to the 1890 virus and not having been exposed earlier to H1N8:

$$
P_{c}(\mathrm{imp})=P_{c}(\sim H 1 N 8) \cdot\left(1-P_{c}(\sim 1890)\right)
$$

This formulation assumes that everybody who was exposed to the 1890 virus as their first flu was imprinted. Alternatively, the $\lambda_{1890}$ parameter can be reinterpreted to instead represent a combined rate of exposure and imprinting conditional on having had no prior H1N8 exposure, with a greater, latent exposure rate.

\footnotetext{
${ }^{11}$ The derivation of these numbers is as follows. Individuals are assumed to be born halfway through their birth year. Those born in the second half of the year spend o time that year being aged $6+$ months. Of the half of the cohort born in the first half of the year, they are born on average 0.25 years into the year, and spend the last 0.25 of the year being $6+$ months old. Averaging the halves of the cohort that average $o$ and that average 0.25 years generates 0.125 . Likewise, individuals born early in their birth year spend their entire second calendar year being $6+$ months old, while those born in the second half of their birth year spend, on average, 0.25 years in their second year being aged $6+$ months; averaging 1 and 0.25 gives .625 average time being $6+$ months old in the second calendar year. These calculations assume that birth cohorts are not rapidly growing or shrinking in size, nor are they excessively seasonal (so that birth are not concentrated early or late in the calendar year).
} 
Finally, the probability of being immunologically refocused on the 1890 flu is the joint probability of having had prior exposure to H1N8, subsequently being exposed to the 1890 flu, and refocusing:

$$
P_{c}(r e f)=\left(1-P_{c}(\sim H 1 N 8)\right) \cdot\left(1-P_{c}(\sim 1890)\right) \cdot \lambda_{r e f}
$$

The $\lambda_{\text {ref }}$ parameter also supports multiple interpretations. Equations S12-S15 as a whole model a situation in which all of those who were exposed to the $1890 \mathrm{flu}$ without prior H1N8 exposure, and only some of those who were exposed to the 1890 flu with prior H1N8 exposure, are "imprinted," which we use as a stand-in for the risk of extremely high mortality in 1918. By calling $\lambda_{\text {ref }}$ the refocusing parameter, we highlight the refocusing hypothesis suggested by Gagnon et al. (2015). However, the same set of equations could instead represent a situation in which deleterious 1890 imprinting occurs equally among all children exposed to the 1890 virus (regardless of prior exposure), but prior H1N8 exposure also confers protection in 1918 as a homotypic exposure, regardless of imprinting-creating intermediate vulnerability for the population with both deleterious imprinting and protective exposure. Under either interpretation, if 1890 exposure is deleterious in 1918 only when it is the first flu exposure, then only the results with $\lambda_{\text {ref }}=0$ model the relevant cohort exposures.

In general, the results show that high rates of immunological imprinting, such as those implied for the cohorts aged 25-29 in 1918, require either (a) moderately high rates of 1890-2 pandemic exposure and either low rates of H1N8 exposure or high rates of immunological refocusing, or (b) if $\mathrm{H} 1 \mathrm{~N} 8$ exposure is high and refocusing is nonexistent or rare, very high rates of 1890-2 pandemic exposure (Figure S3). This is sensible: if refocusing is rare, then the 1890 'sin' would be 'original' only in those who had not had a prior H1N8 exposure, which would be less likely if such exposures were common. However, the combinations of rates compatible with the imputed imprinting prevalence for the 20 s and 30 s are distinct. This reflects different years of potential exposure (for the cohorts in their 20s, little to no H1N8 exposure prior to 1890 and sometimes limited duration of exposure in 1890-1892; for the cohorts in their 30s, potentially a great deal of $\mathrm{H} 1 \mathrm{~N} 8$ exposure prior to 1890 and exposure for all of 1890-1892) and different imputed imprinting prevalence (from the first stage of simulations).

The main result for cohorts aged 25-29 in 1918 is that the annual 1890 exposure rates derived from the assumption of cumulative imprinting $P_{c}(\mathrm{imp}) \geq 85 \%$ in the cohort have a minimum value of $\lambda_{1890} \geq 47 \%$, with or without refocusing. For the 
cohorts who would have been ages 25-29 in 1918, the H1N8 rate produces relatively little constraint since those cohorts had few (or no) years in which to accrue exposure prior to 1890. For example, restricting the annual H1N8 exposure rate to $\lambda_{H 1 N 8} \geq 30 \%$ (extremely high for seasonal flu) raises the minimum 1890 exposure rate to $\lambda_{1890} \geq 51 \%$ without refocusing, or $\lambda_{1890} \geq 48 \%$ with refocusing. These 1890 exposure rates are high, although broadly within the bounds of the attack rates estimated for the 1890 flu at its height (Valleron et al. 2010), or for pandemic (Mathews et al. 2009, p. 147; SaundersHastings and Krewski 2016, p. 7) influenza attack rates generally, and are not outlandishly higher than seasonal influenza attack rates for children (Molinari et al. 2007) and contemporary estimates of seasonal influenza attack rates during a bad flu season in the U.S. population with partial vaccination (Chunara et al. 2015).

The cohorts who were in their 30 in 1918 had more years of potential exposure to H1N8 before 1890. Even so, with an estimated lower bound imprinting prevalence of only around $P_{c}(\mathrm{imp}) \approx 35-40 \%$ needed to potentially account for high 1918 mortality, our simulation results for these cohorts are far less constrained than for the younger cohorts. For the cohorts aged 30-39 in 1918, to reach an imprinting prevalence of $P_{c}(\mathrm{imp}) \geq 35 \%$ requires a minimum annual 1890-virus exposure rate of only $\lambda_{1890} \geq$ $14 \%$. Restricting the H1N8 rate to $\lambda_{H 1 N 8} \geq 30 \%$ still raises the minimum 1890 exposure to only $\lambda_{1890} \geq 18 \%$ without refocusing, or $\lambda_{1890} \geq 15 \%$ with refocusing. ${ }^{12}$

In general, these simulation results seem to suggestively narrow down the possibility space of historical exposures to flu and prevalence of immunological imprinting among key cohorts, especially those aged 25-29 in 1918. However, the results do not appear to be clearly outside of the boundaries of plausibility. Across our various empirical and simulation analyses, we are not able to disconfirm the immunological imprinting hypothesis.

\footnotetext{
12 The estimated minimum 1890 attack rates are barely affected by restricting the scenarios to those whose in which $\mathrm{H} 1 \mathrm{~N} 8$ seasonal attack rates are such as to produce cumulative incidence similar to rough estimates assumed in simulations by Worobey et al. (2014, p. 8109) of o\% at age $0,50 \%$ at age 7 , and $100 \%$ at age 14 . However, our model that assumes constant attack rates over age can only reproduce cumulative incidence rates that are very roughly in this ballpark (since constant rates are incompatible with a linear decline in cumulative incidence). Our closest fit is at $\lambda_{H 1 N 8}=.16$, which generates estimates of $\lambda_{1890} \geq 49 \%$ and $\lambda_{1890} \geq 16 \%$ for $30-39$-year-olds, hardly different from our main results.
} 


\section{Supplemental Tables}

Association between socio-demographic characteristics and mortality disparities

\begin{tabular}{llllllllll}
\hline \multicolumn{10}{c}{$\log$ (mortality ratio) } \\
1 & 2 & 3 & 4 & 5 & 6 & 7 & 8 \\
\hline
\end{tabular}

Dissimilarity index .112

Divergence index $-2.473$

$(1.816)$

Variance ratio index $-.206$ (.430)

Sequence index $-.613$ (.396)

Ave. number per dwelling (log ratio)

$\%$ living in multifamily homes (log ratio)

illiteracy rate (log ratio) $-.034$ $(.041)$

Air pollution (10-mile radius)

$\log \left(\right.$ baseline mortality ratio) $\quad .345^{* *} \quad .422^{* * *} \quad .365^{* *} \quad .439^{* * *} \quad .345^{* *} \quad .339^{* *} \quad .396^{* *} \quad .357^{* *}$

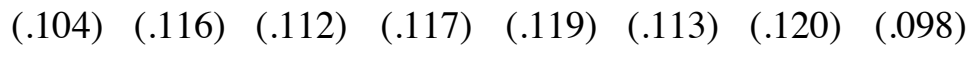

$\%$ aged $20-39$

$$
\begin{array}{llllllll}
3.139 & 4.028 & 3.392 & 2.447 & 3.279 & 2.791 & 3.620 & 3.665 \\
(3.055) & (2.988) & (3.024) & (2.956) & (3.614) & (3.382) & (3.022) & (2.957)
\end{array}
$$




\begin{tabular}{lccccccccc} 
NPI duration & -.002 & -.003 & -.002 & -.003 & -.002 & -.002 & -.002 & -.003 \\
& $(.001)$ & $(.001)$ & $(.001)$ & $(.001)$ & $(.002)$ & $(.002)$ & $(.002)$ & $(.001)$ \\
NPI delay & .010 & .008 & .010 & .004 & .012 & .012 & .008 & .010 \\
& $(.008)$ & $(.008)$ & $(.008)$ & $(.009)$ & $(.009)$ & $(.009)$ & $(.009)$ & $(.009)$ \\
Constant & -1.231 & -1.364 & -1.225 & -.397 & -1.266 & -1.070 & -1.327 & -1.391 \\
& $(1.159)$ & $(1.130)$ & $(1.155)$ & $(1.238)$ & $(1.392)$ & $(1.292)$ & $(1.153)$ & $(1.137)$ \\
Observations & 36 & 36 & 36 & 36 & 31 & 31 & 36 & 35 \\
$\mathrm{R}^{2}$ & .339 & .377 & .343 & .387 & .343 & .364 & .353 & .411 \\
Adjusted R & \\
Residual Std. Error & .229 & .273 & .234 & .285 & .212 & .237 & .245 & .310 \\
F Statistic & .301 & .292 & .300 & .290 & .318 & .313 & .298 & .283 \\
\hline Notes: & $3.082^{*}$ & $3.623^{*}$ & $3.133^{*}$ & $3.787^{* *}$ & $2.614^{*}$ & $2.864^{*}$ & $3.267^{*}$ & $4.050^{* *}$ \\
\hline
\end{tabular}

Table S1: Results of modeling mortality on city-specific indices of segregation, residential density, illiteracy. And air pollution. Baseline mortality is calculated from 1910-1917 trends by city. All models control for the percentage of residents aged 20-3 and city-specific NPIs. 
Association between NPI implementation and mortality

\begin{tabular}{|c|c|c|c|c|c|c|c|c|}
\hline & \multicolumn{6}{|c|}{$\log$ (mortality) } & \multicolumn{2}{|c|}{$\begin{array}{l}\log (\text { mortality } \\
\text { ratio })\end{array}$} \\
\hline & Total & Total & Nonwhite & Nonwhite & White & White & & \\
\hline & 1 & 2 & 3 & 4 & 5 & 6 & 7 & 8 \\
\hline \multirow[t]{2}{*}{ NPI duration } & -0.000 & .004 & -.002 & .003 & .001 & .007 & -.002 & -.003 \\
\hline & $(.001)$ & $(.003)$ & $(.001)$ & $(.003)$ & $(.002)$ & $(.004)$ & $(.001)$ & $(.003)$ \\
\hline \multirow[t]{2}{*}{ NPI delay } & .008 & .041 & .011 & $.050^{*}$ & .001 & .053 & .010 & .002 \\
\hline & $(.007)$ & $(.021)$ & $(.008)$ & $(.023)$ & $(.010)$ & $(.029)$ & $(.008)$ & $(.025)$ \\
\hline \multirow[t]{2}{*}{ NPI duration*delay } & & -0.000 & & -0.000 & & -.001 & & 0.000 \\
\hline & & $(0.000)$ & & $(0.000)$ & & $(0.000)$ & & $(0.000)$ \\
\hline \multirow[t]{2}{*}{$\begin{array}{l}\log \text { (baseline } \\
\text { mortality) }\end{array}$} & $.752^{* * *}$ & $.724^{* * *}$ & $.590^{* * *}$ & $.561^{* * *}$ & $.509^{* * *}$ & $.496^{* * *}$ & & \\
\hline & $(.109)$ & $(.107)$ & $(.106)$ & $(.104)$ & $(.124)$ & $(.120)$ & & \\
\hline \multirow[t]{2}{*}{$\begin{array}{l}\log (\text { baseline } \\
\text { mortality ratio) }\end{array}$} & & & & & & & $.362^{* *}$ & $.365^{* *}$ \\
\hline & & & & & & & $(.101)$ & $(.103)$ \\
\hline \multirow[t]{2}{*}{ Constant } & $2.542^{* * *}$ & $2.340^{* * *}$ & $3.378^{* * *}$ & $3.128^{* * *}$ & $3.911^{* * *}$ & $3.420^{* * *}$ & .008 & .091 \\
\hline & $(.592)$ & $(.589)$ & $(.592)$ & $(.590)$ & $(.622)$ & $(.650)$ & $(.169)$ & $(.297)$ \\
\hline Observations & 36 & 36 & 36 & 36 & 36 & 36 & 36 & 36 \\
\hline $\mathrm{R}^{2}$ & .599 & .631 & .515 & .560 & .349 & .418 & .312 & .315 \\
\hline Adjusted $\mathrm{R}^{2}$ & .561 & .584 & .470 & .504 & .288 & .343 & .248 & .227 \\
\hline Residual Std. Error & .261 & .254 & .285 & .276 & .362 & .347 & .297 & .301 \\
\hline F Statistic & $15.915^{* * *}$ & $13.272^{* * * *}$ & $\left.11.330^{* * *}\right)$ & $9.883^{* * *}$ & $5.712^{* *}$ & $5.569^{* *}$ & $4.845^{* *}$ & $3.563^{*}$ \\
\hline
\end{tabular}

Notes: $\quad{ }^{*} \mathrm{P}<.05 ;{ }^{* *} \mathrm{P}<.01 ;{ }^{* * *} \mathrm{P}<.001$

Table S2. Results of modeling logged mortality (models 1-6) and logged mortality ratios (models 7-8) on non-pharmaceutical interventions (NPI). Models 1 and 2 use total mortality; models 3-6 are race-specific. NPIs include bans on public gatherings and mandatory closures of schools, theaters, bars, and restaurants. NPI duration measures the total number of NPI days per city; NPI delay measures the difference, in days, between the onset of local infections and the first NPI. 


\begin{tabular}{|c|c|c|c|c|c|c|}
\hline Hypothesis & $\begin{array}{l}\text { Prior exposure } \\
\text { protective or } \\
\text { harmful? }\end{array}$ & $\begin{array}{l}\text { Which prior } \\
\text { exposure? }\end{array}$ & $\begin{array}{l}\text { Exposure in } \\
\text { which } \\
\text { years? }\end{array}$ & $\begin{array}{l}\text { Youngest cohort } \\
\text { likely to be } \\
\text { affected }\end{array}$ & $\begin{array}{l}\text { Oldest cohort likely } \\
\text { to be affected }\end{array}$ & Canonical citations \\
\hline V1: Herald wave & Protective & $\begin{array}{l}1918 \mathrm{flu} \\
(\mathrm{H} 1 \mathrm{~N} 1)\end{array}$ & 1918 & No limit & No limit & $\begin{array}{l}\text { Crosby 2003; Økland } \\
\text { and Mamelund } 2019\end{array}$ \\
\hline V2: Early “1918” flu & Protective & $\begin{array}{l}1918 \mathrm{flu} \\
(\mathrm{H} 1 \mathrm{~N} 1)\end{array}$ & 1915-1918 & No limit & No limit & Worobey et al. 2019 \\
\hline $\begin{array}{l}\text { V3: H1 partial immunity } \\
\text { vs. "H1-naïve" }\end{array}$ & Protective & Any $\mathrm{H} 1$ virus & $\begin{array}{l}1900-1918 \\
\text { and pre-1889 }\end{array}$ & $\begin{array}{l}\text { No hard limit; older } \\
\text { is generally more } \\
\text { plausible }\end{array}$ & $\begin{array}{l}\text { No hard limit, but } \\
\text { younger is generally } \\
\text { more plausible }\end{array}$ & Worobey et al. 2014 \\
\hline V4: Fetal harms & Harmful & $\begin{array}{l}1890 \text { flu } \\
\text { ("Russian") }\end{array}$ & $1889-1893$ & $\begin{array}{l}1895 \text { birth; } 1892 \\
\text { more likely }\end{array}$ & 1890 birth & Gagnon et al. 2013 \\
\hline $\begin{array}{l}\text { V5: Original antigenic } \\
\text { sin (immunological } \\
\text { imprinting) }\end{array}$ & Harmful & $\begin{array}{l}1890 \text { flu } \\
\text { ("Russian") }\end{array}$ & $1889-1893$ & $\begin{array}{l}1895 \text { birth; } 1892 \\
\text { more likely }\end{array}$ & $\begin{array}{l}\sim 1885 \text { birth; younger } \\
\text { is more plausible }\end{array}$ & $\begin{array}{l}\text { Gagnon et al. 2013; } \\
\text { Hallman and Gagnon } \\
\text { 2014; Luk et al. 2001; } \\
\text { Mamelund 2011; Shanks } \\
\text { and Brundage 2012; } \\
\text { Worobey et al. 2014 }\end{array}$ \\
\hline $\begin{array}{l}\text { V6: Original antigenic } \\
\text { sin plus immunological } \\
\text { refocusing }\end{array}$ & Harmful & $\begin{array}{l}1890 \text { flu } \\
\text { ("Russian") }\end{array}$ & $1889-1893$ & $\begin{array}{l}1895 \text { birth; } 1892 \\
\text { more likely }\end{array}$ & $\begin{array}{l}1860 \text { birth, but with } \\
\text { declining prevalence } \\
\text { for older cohorts }\end{array}$ & Gagnon et al. 2015 \\
\hline
\end{tabular}


Table S3. Social immunology hypotheses purporting to explain reduced racial disparities in 1918 urban pandemic mortality based on greater nonwhite protective exposure to earlier flu viruses $\left(\mathrm{V}_{1}-\mathrm{V}_{3}\right)$ or greater white harmful exposure to earlier flu viruses (V4-V6). Hypotheses are listed in order of how early the putatively beneficial exposure is proposed to begin ( $\left.\mathrm{V}_{1}-\mathrm{V}_{3}\right)$ or how late the putatively harmful exposure is proposed to end (V4-V6) such that later-numbered hypotheses within each set imply an immunological mechanism acting over a greater number of periods or cohorts. Our article focuses on V1, V5, and V6 as the most testable hypotheses. 


\section{Association between herald wave exposure and pandemic mortality}

\begin{tabular}{|c|c|c|c|c|c|c|}
\hline & \multicolumn{4}{|c|}{$\log ($ mortality $)$} & \multicolumn{2}{|c|}{$\log ($ mortality ratio) } \\
\hline & \multicolumn{2}{|c|}{ Nonwhite Nonwhite } & \multirow{2}{*}{$\begin{array}{c}\text { White } \\
3\end{array}$} & \multirow{2}{*}{$\begin{array}{c}\text { White } \\
4\end{array}$} & \multirow[b]{2}{*}{5} & \multirow[b]{2}{*}{6} \\
\hline & 1 & 2 & & & & \\
\hline \multirow[t]{2}{*}{$\log$ (herald wave mortality) } & -.033 & -.051 & $.389^{*}$ & .392 & & \\
\hline & $(.098)$ & $(.103)$ & $(.178)$ & $(.209)$ & & \\
\hline \multirow[t]{2}{*}{$\log$ (herald wave mortality ratio) } & & & & & .038 & .008 \\
\hline & & & & & $(.091)$ & $(.094)$ \\
\hline \multirow[t]{2}{*}{$\%$ aged $20-39$} & -.778 & 2.958 & -2.228 & -1.752 & -.938 & -.701 \\
\hline & $(1.788)$ & $(2.901)$ & $(3.354)$ & $(4.062)$ & $(1.837)$ & $(2.132)$ \\
\hline \multirow[t]{2}{*}{ NPI delay } & & .004 & & .004 & & -.014 \\
\hline & & $(.013)$ & & $(.014)$ & & $(.007)$ \\
\hline \multirow[t]{2}{*}{ NPI duration } & & -.004 & & -.001 & & .001 \\
\hline & & $(.003)$ & & $(.002)$ & & $(.001)$ \\
\hline \multirow[t]{2}{*}{ Constant } & $6.683^{* * *}$ & $5.421^{* *}$ & $5.218^{* *}$ & $5.066^{*}$ & .713 & .815 \\
\hline & $(1.005)$ & $(1.350)$ & $(1.672)$ & (1.934) & $(.737)$ & $(.904)$ \\
\hline Observations & 20 & 17 & 20 & 17 & 20 & 17 \\
\hline $\mathrm{R}^{2}$ & .016 & .172 & .281 & .340 & .032 & .291 \\
\hline Adjusted $\mathrm{R}^{2}$ & -.100 & -.105 & .196 & .121 & -.081 & .054 \\
\hline Residual Std. Error & .281 & .290 & .277 & .305 & .162 & .151 \\
\hline F Statistic & .138 & .621 & 3.319 & 1.549 & .285 & 1.228 \\
\hline
\end{tabular}

Table S4. Results of modeling the effect of exposure to the spring 1918 herald wave (January-June) on mortality and mortality ratios during the 1918 pandemic (September-December). Models 1-4 show racespecific associations. Models 2, 4, and 6 control for NPI implementation (measured in days). 
Association between childhood urban residency and pandemic mortality for ages 20-39

\begin{tabular}{|c|c|c|c|c|c|c|}
\hline & \multicolumn{4}{|c|}{$\log$ (mortality) } & \multicolumn{2}{|c|}{$\log ($ mortality ratio $)$} \\
\hline & Nonwhite & Nonwhite & White & White & & \\
\hline & 1 & 2 & 3 & 4 & 5 & 6 \\
\hline \multirow[t]{2}{*}{$\%$ urban in 1900} & .442 & .272 & .509 & .897 & $-.610^{*}$ & -.698 \\
\hline & $(.397)$ & $(.388)$ & $(.521)$ & $(.622)$ & $(.265)$ & $(.375)$ \\
\hline \multirow[t]{2}{*}{ NPI duration } & & -.003 & & -.002 & & 0.000 \\
\hline & & $(.001)$ & & $(.003)$ & & $(.002)$ \\
\hline \multirow[t]{2}{*}{ NPI delay } & & .011 & & .012 & & -.005 \\
\hline & & $(.008)$ & & $(.016)$ & & $(.011)$ \\
\hline \multirow[t]{2}{*}{$\log ($ baseline mortality for ages $20-39$ ) } & $.354^{*}$ & $.347^{* *}$ & .221 & .297 & & \\
\hline & $(.119)$ & $(.100)$ & $(.193)$ & $(.226)$ & & \\
\hline \multirow[t]{2}{*}{$\log ($ baseline mortality ratio for ages $20-39)$} & & & & & $-.227^{*}$ & -.151 \\
\hline & & & & & $(.104)$ & $(.144)$ \\
\hline \multirow[t]{2}{*}{ Constant } & $4.640^{* * *}$ & $4.840^{* * *}$ & $5.443^{* * *}$ & $4.911^{* * *}$ & $.847^{* *}$ & $.873^{*}$ \\
\hline & $(.678)$ & $(.582)$ & $(.680)$ & $(.885)$ & $(.278)$ & $(.349)$ \\
\hline Observations & 17 & 14 & 17 & 14 & 17 & 14 \\
\hline $\mathrm{R}^{2}$ & .411 & .661 & .221 & .462 & .352 & .403 \\
\hline Adjusted $\mathrm{R}^{2}$ & .327 & .511 & .109 & .223 & .260 & .137 \\
\hline Residual Std. Error & .203 & .164 & .325 & .324 & .184 & .211 \\
\hline F Statistic & $4.880^{*}$ & $4.390^{*}$ & 1.983 & 1.932 & $3.811^{*}$ & 1.516 \\
\hline
\end{tabular}

Table S5: Association between 1900 urban residency status and 1918 mortality. Residency status, mortality, and baseline mortality (calculated on the basis of 1910-1917 trends) are for those aged 20-39 (in 1918) only. 


\section{Supplemental Figures}

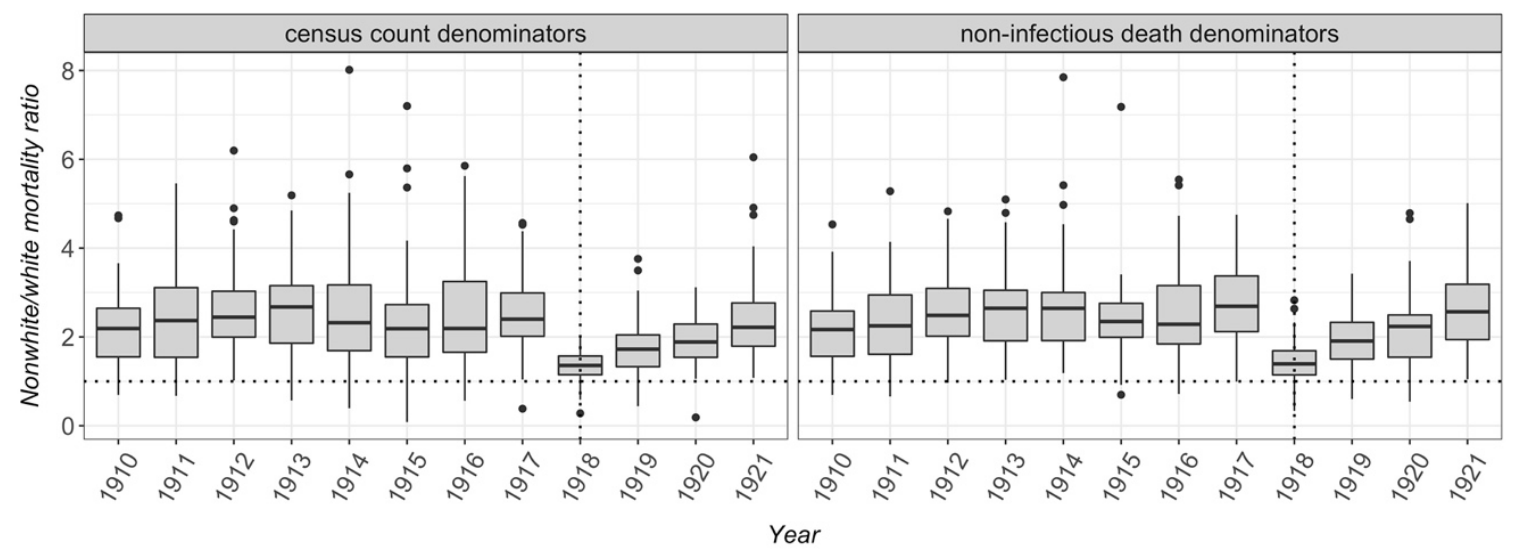

Figure S1. Annual mortality disparities, in ratio scale, based alternatively on census count denominators and non-infectious death count denominators. 

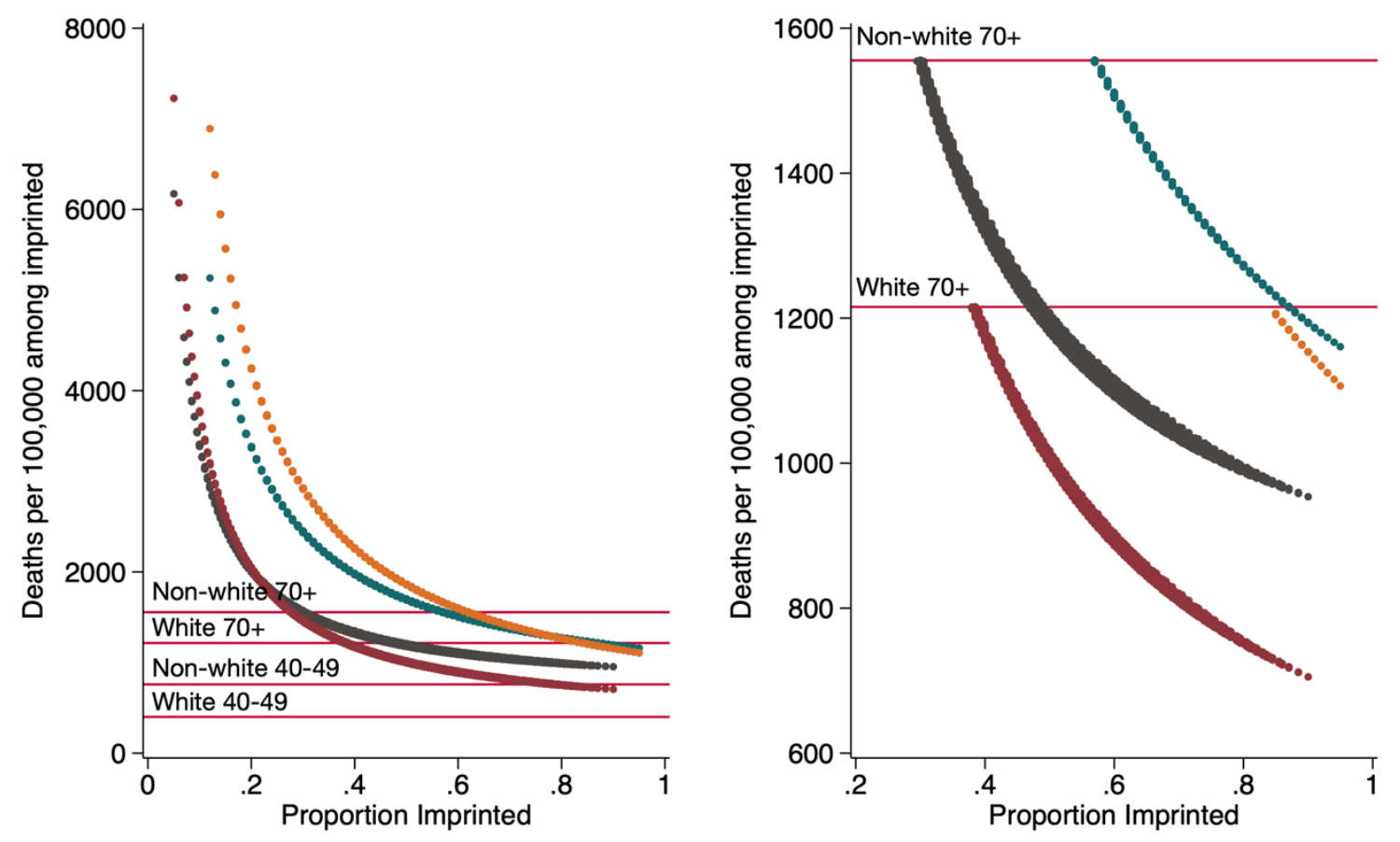

\section{- Nonwhite 20s - White 20s \\ - Nonwhite 30s - White 30s}

Figure S2. Mortality of imprinted individuals as a function of the portion of the 20-29 age group assumed to be imprinted, by race. Horizontal bands reflect (bottom to top) non-white and white mortality in the 40-49 and 70+ age groups, respectively. The left panel portrays all simulated cohorts; the right panel is limited to those in which hypothetical mortality of the imprinted in the 20-29 or 30-39 age band is below the same-race mortality at age $70+$. In the right panel, the points along the $\mathrm{x}$-axis at which the white curves hit the white $70+$ mortality level become the inputs for the second stage of simulations. 


\section{Exposure rates consistent with derived imprinting rates, by refocusing rate}
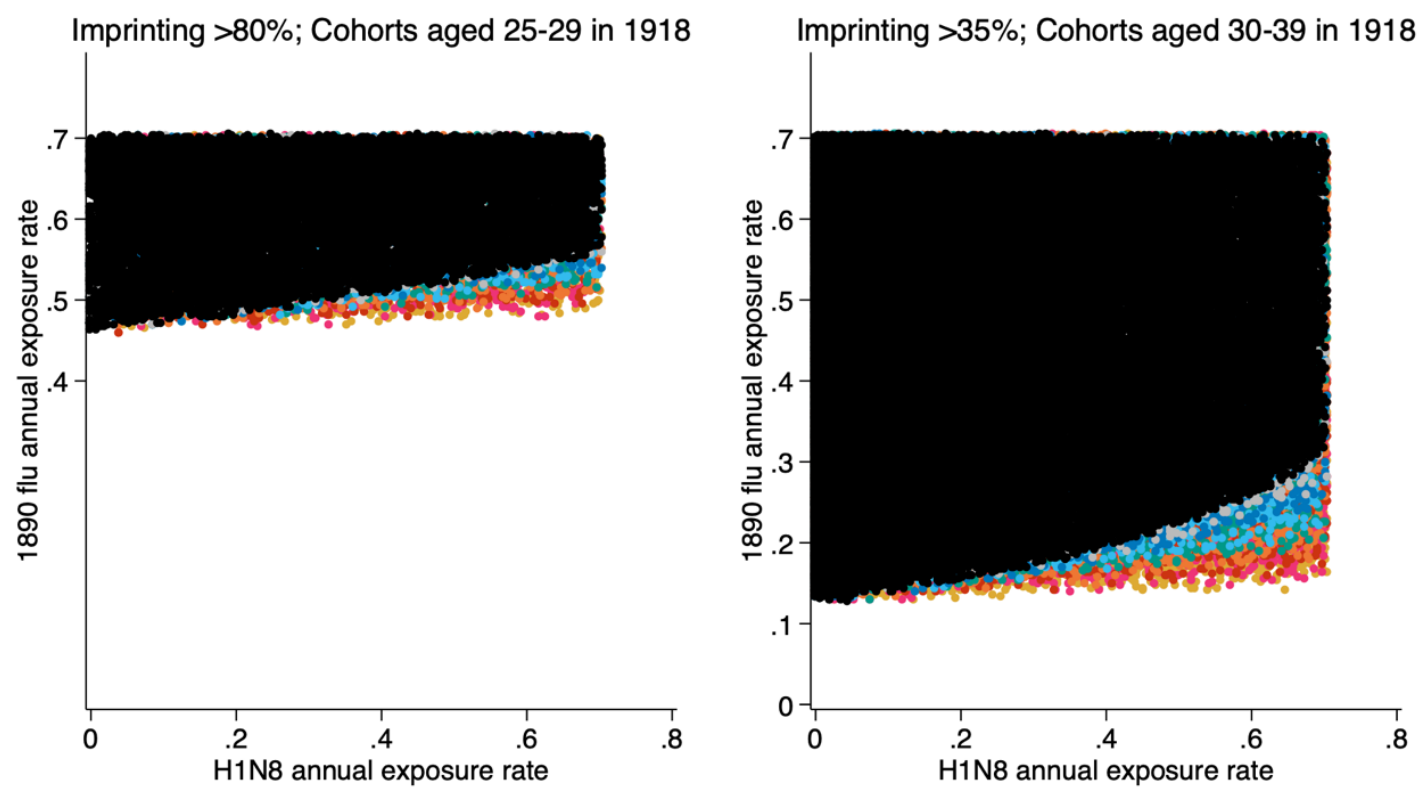

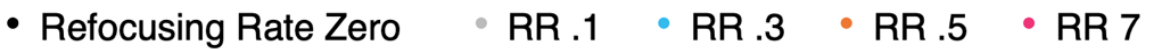

$$
\begin{aligned}
& \text { - RR .2 • RR .4 } 4 \text { RR .6 } 6 \text { RR .8 }
\end{aligned}
$$

Figure $S_{3}$. Annual flu exposure and immunological refocusing rates consistent with urban white immunological imprinting rate derived from simulations for cohorts whose ages in 1918 were 25-29 (left panel) and 30-39 (right panel), respectively. Points are jittered and layered so that those with higher refocusing rates (which impose the least stringent restrictions on the other two parameters) are underneath the more constrained, low- or no-refocusing points. 


\section{APPENDIX REFERENCES}

Abramitszky, R., Boustan, L., \& Myera, R. (2020). Census Linking Project: Version 1.0 [dataset]. https://censuslinkingproject.org

Abramitzky, R., Boustan, L., Eriksson, K., Feigenbaum, J., \& Pérez, S. (2021). Automated Linking of Historical Data. Journal of Economic Literature, 59(3), 865-918. https://doi.org/10.1257/jel.20201599

Britten, R. H. (1932). The Incidence of Epidemic Influenza, 1918-19: A Further Analysis According to Age, Sex, and Color of the Records of Morbidity and Mortality Obtained in Surveys of 12 Localities. Public Health Reports (1896-1970), 47(6), 303. https://doi.org/10.2307/4580340

Brundage, J. F., \& Shanks, G. D. (2008). Deaths from Bacterial Pneumonia during 1918-19 Influenza Pandemic. Emerging Infectious Diseases, 14(8), 1193-1199. https://doi.org/10.3201/eid1408.071313

Chunara, R., Goldstein, E., Patterson-Lomba, O., \& Brownstein, J. S. (2015). Estimating influenza attack rates in the United States using a participatory cohort. Scientific Reports, 5(1), 9540. https://doi.org/10.1038/srep09540

Crosby, A. W. (2003). America's forgotten pandemic: the influenza of 1918. Cambridge, England: Cambridge University Press.

Dorman, R. (2008). The Creation and Destruction of the 1890 Federal Census. The American Archivist, 71(2), 350-383. https://doi.org/10.17723/aarc.71.2.c600075v1q5x0004

Dowdle, W. R. (1999). Influenza A virus recycling revisited. Bulletin of the World Health Organization, 77(10), 820-828.

Dublin, L. I., Davis, W. H., Batt, W. R., Hoffman, F. L., Haines, B. M., \& Lloyd, B. J. (1928). The Growth of the Birth and Death Registration Areas: Report of the Committee. American Journal of Public Health and the Nations Health, 18(5), 606-608. https://doi.org/10.2105/AJPH.18.5.606

Feigenbaum, J. J., Muller, C., \& Wrigley-Field, E. (2019). Regional and Racial Inequality in Infectious Disease Mortality in U.S. Cities, 1900-1948. Demography, 56(4), 1371-1388. https://doi.org/10.1007/s13524-019-00789-z

Francis, T. (1960). On the Doctrine of Original Antigenic Sin. Proceedings of the American Philosophical Society, 104(6), 572-578.

Frost, W. H. (1920). Statistics of Influenza Morbidity-With Special Reference to Certain Factors in Case Incidence and Case Fatality. Public Health Reports (1896-1970), 35(11), 584-597.

Gagnon, A., Acosta, J. E., Madrenas, J., \& Miller, M. S. (2015). Is Antigenic Sin Always "Original?" Re-examining the Evidence Regarding Circulation of a Human H1 Influenza Virus Immediately Prior to the 1918 Spanish Flu. PLOS Pathogens, 11(3), e1004615. https://doi.org/10.1371/journal.ppat.1004615 
Gagnon, A., Miller, M. S., Hallman, S. A., Bourbeau, R., Herring, D. A., Earn, D. JD., \& Madrenas, J. (2013). Age-Specific Mortality During the 1918 Influenza Pandemic: Unravelling the Mystery of High Young Adult Mortality. PLoS ONE, 8(8), e69586. https://doi.org/10.1371/journal.pone.0069586

Gostic, K. M., Ambrose, M., Worobey, M., \& Lloyd-Smith, J. O. (2016). Potent protection against H5N1 and H7N9 influenza via childhood hemagglutinin imprinting. Science, 354(6313), 722-726. https://doi.org/10.1126/science.aag1322

Gostic, K. M., Bridge, R., Brady, S., Viboud, C., Worobey, M., \& Lloyd-Smith, J. O. (2019). Childhood immune imprinting to influenza A shapes birth year-specific risk during seasonal H1N1 and H3N2 epidemics. PLOS Pathogens, 15(12), e1008109. https://doi.org/10.1371/journal.ppat.1008109

Grantz, K. H., Rane, M. S., Salje, H., Glass, G. E., Schachterle, S. E., \& Cummings, D. A. T. (2016). Disparities in influenza mortality and transmission related to sociodemographic factors within Chicago in the pandemic of 1918. Proceedings of the National Academy of Sciences, 113(48), 13839-13844. https://doi.org/10.1073/pnas.1612838113

Hallman, S., \& Gagnon, A. (2014). Does Exposure to Influenza Very Early in Life Affect Mortality Risk during a Subsequent Outbreak? The 1890 and 1918 Pandemics in Canada. In M. K. Zuckerman (Ed.), Modern Environments and Human Health (pp. 123-135). Oxford: John Wiley \& Sons, Inc. https://doi.org/10.1002/9781118504338.ch7

Hoehn-Velasco, L., \& Wrigley-Field, E. (2021). City health departments, public health expenditures, and urban mortality over 1910-1940. Economic Inquiry, ecin.13038. https://doi.org/10.1111/ecin.13038

Ireland, Merritte W. (1929). The Medical Department of the United States Army in the World War, Vol. IX. Washington, D.C.: Government Printing Office.

Kramer, H. D. (1947). The Beginnings of the Public Health Movement in the United States. Bulletin of the History of Medicine, 21(3), 352-376.

Kramer, H. D. (1950). Early Municipal and State Boards of Health. Bulletin of the History of Medicine, 24(6), 503-529.

Krishnan, L., Ogunwole, S. M., \& Cooper, L. A. (2020). Historical Insights on Coronavirus Disease 2019 (COVID-19), the 1918 Influenza Pandemic, and Racial Disparities: Illuminating a Path Forward. Annals of Internal Medicine, 173(6), 474-481. https://doi.org/10.7326/M20-2223

Luk, J., Gross, P., \& Thompson, W. W. (2001). Observations on Mortality during the 1918 Influenza Pandemic. Clinical Infectious Diseases, 33(8), 1375-1378. https://doi.org/10.1086/322662

Mamelund, S.-E. (2011). Geography May Explain Adult Mortality from the 1918-20 Influenza Pandemic. Epidemics, 3(1), 46-60. https://doi.org/10.1016/j.epidem.2011.02.001

Markel, H., Lipman, H. B., Navarro, J. A., Sloan, A., Michalsen, J. R., Stern, A. M., \& Cetron, M. S. (2007). Nonpharmaceutical Interventions Implemented by US Cities During the 1918-1919 Influenza Pandemic. JAMA, 298(6), 644.

https://doi.org/10.1001/jama.298.6.644 
Mathews, J. D., Chesson, J. M., McCaw, J. M., \& McVernon, J. (2009). Understanding influenza transmission, immunity and pandemic threats. Influenza and Other Respiratory Viruses, 3(4), 143-149. https://doi.org/10.1111/j.1750-2659.2009.00089.x

McBride, D. (2018). Caring for Equality: A History of African American Health and Healthcare. Lanham, MD: Rowman \& Littlefield.

Molinari, N.-A. M., Ortega-Sanchez, I. R., Messonnier, M. L., Thompson, W. W., Wortley, P. M., Weintraub, E., \& Bridges, C. B. (2007). The annual impact of seasonal influenza in the US: Measuring disease burden and costs. Vaccine, 25(27), 5086-5096. https://doi.org/10.1016/j.vaccine.2007.03.046

Monto, A. S., Malosh, R. E., Petrie, J. G., \& Martin, E. T. (2017). The Doctrine of Original Antigenic Sin: Separating Good From Evil. The Journal of Infectious Diseases, 215(12), 1782-1788. https://doi.org/10.1093/infdis/jix173

Morens, D. M., Taubenberger, J. K., \& Fauci, A. S. (2008). Predominant Role of Bacterial Pneumonia as a Cause of Death in Pandemic Influenza: Implications for Pandemic Influenza Preparedness. The Journal of Infectious Diseases, 198(7), 962-970. https://doi.org/10.1086/591708

Økland, H., \& Mamelund, S.-E. (2019). Race and 1918 Influenza Pandemic in the United States: A Review of the Literature. International Journal of Environmental Research and Public Health, 16(14), E2487. https://doi.org/10.3390/ijerph16142487

Ruggles, S., Flood, S., Goeken, R., Grover, J., Meyer, E., Pacas, J., \& Sobek, M. (2020). IPUMS USA: Version 10.0 [dataset]. IPUMS. https://www.ipums.org

Saunders-Hastings, P., \& Krewski, D. (2016). Reviewing the History of Pandemic Influenza: Understanding Patterns of Emergence and Transmission. Pathogens, 5(4), 66. https://doi.org/10.3390/pathogens5040066

Schlabach, E. (2019). The Influenza Epidemic and Jim Crow Public Health Policies and Practices in Chicago, 1917-1921. The Journal of African American History, 104(1), 3158. https://doi.org/10.1086/701105

Shanks, G. D., \& Brundage, J. F. (2012). Pathogenic Responses among Young Adults during the 1918 Influenza Pandemic. Emerging Infectious Diseases, 18(2), 201-207. https://doi.org/10.3201/eid1802.102042

Shanks, G. D., MacKenzie, A., Waller, M., \& Brundage, J. F. (2012). Relationship between "purulent bronchitis" in military populations in Europe prior to 1918 and the 1918-1919 influenza pandemic: Precursors of pandemic influenza. Influenza and Other Respiratory Viruses, 6(4), 235-239. https://doi.org/10.1111/j.1750-2659.2011.00309.x

Valleron, A.-J., Cori, A., Valtat, S., Meurisse, S., Carrat, F., \& Boelle, P.-Y. (2010). Transmissibility and geographic spread of the 1889 influenza pandemic. Proceedings of the National Academy of Sciences, 107(19), 8778-8781.

https://doi.org/10.1073/pnas.1000886107

Viboud, C., \& Epstein, S. L. (2016). First flu is forever. Science, 354(6313), 706-707. https://doi.org/10.1126/science.aak9816 
Viboud, C., Gostic, K., Nelson, M. I., Price, G. E., Perofsky, A., Sun, K., et al. (2020). Beyond clinical trials: Evolutionary and epidemiological considerations for development of a universal influenza vaccine. PLOS Pathogens, 16(9), e1008583. https://doi.org/10.1371/journal.ppat.1008583

Worobey, M., Han, G.-Z., \& Rambaut, A. (2014). Genesis and pathogenesis of the 1918 pandemic H1N1 influenza A virus. Proceedings of the National Academy of Sciences, 111(22), 8107-8112. https://doi.org/10.1073/pnas.1324197111

Worobey, Michael, Cox, J., \& Gill, D. (2019). The origins of the great pandemic. Evolution, Medicine, and Public Health, 2019(1), 18-25. https://doi.org/10.1093/emph/eoz001

Zhang, A., Stacey, H. D., Mullarkey, C. E., \& Miller, M. S. (2019). Original Antigenic Sin: How First Exposure Shapes Lifelong Anti-Influenza Virus Immune Responses. The Journal of Immunology, 202(2), 335-340. https://doi.org/10.4049/jimmunol.1801149 